\title{
Gene expression for HIV-associated dementia and HIV encephalitis in microdissected neurons I: preliminary analysis
}

This article was published in the following Dove Press journal:

Neurobehavioral HIV Medicine

18 July 201 I

Number of times this article has been viewed

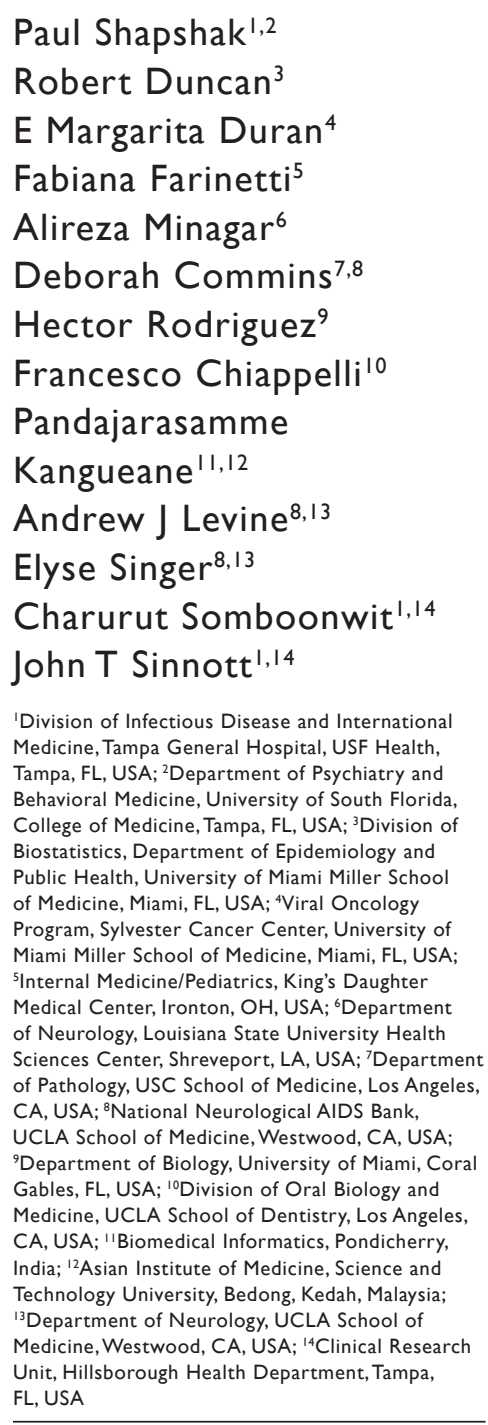

Correspondence: Paul Shapshak

Division of Infectious Disease and International

Medicine, Tampa General Hospital, USF Health,

2 Columbia Drive, Tampa, FL 3360I-I289, USA

Tel + I 8437540702

Fax +18138448013

Email pshapshak@gmail.com
Abstract: We analyzed gene expression in neurons from 16 cases divided into four groups, ie, human immunodeficiency virus (HIV)-associated dementia (HAD)/HIV encephalitis (HAD/ HIVE), HAD alone, HIVE alone, and HIV positive alone. We produced the neurons using laser capture microdissection from cryopreserved basal ganglia (specifically globus pallidus). Gene expression in pooled neurons from each case was analyzed on GE CodeLink Microarray chips with 55,000 gene fragments per chip. One-way analysis of variance showed significant changes in expression of 197 genes among the four groups $(P<0.005)$. The three groups, ie, HAD/HIVE, HAD alone, and HIVE alone, were compared with the HIV-positive group using Fisher's least significant difference test, and associated gene expression changes were assigned to each of the three comparisons. Identified genes were associated with 159 functional categories and many of the genes had more than one function. The functional groups included adhesion, amyloid, apoptosis, channel complex, cell cycle, chaperone, chromatin, cytokine, cytoskeleton, metabolism, mitochondria, multinetwork detection protein, sensory perception, receptor, ribosome, noncoding miRNA, signaling, synapse, transcription factor, homeobox, transport, multidrug resistance, and ubiquitin cycle. Several genes were associated with other neurodegenerative and developmental diseases, including Alzheimer's disease, Huntington's disease, and diGeorge syndrome. Thus, a wide range of dysregulated biochemical processes was reported in neuroanatomically precise neurons. This line of investigation is useful and provides specific information about gene expression dysfunction in NeuroAIDS.

Keywords: NeuroAIDS, human immunodeficiency virus, dementia, encephalitis, laser capture microdissection, globus pallidus, neuron, genes, expression

\section{Introduction}

The term "NeuroAIDS" has been used generally to describe the involvement of the central nervous system in human immunodeficiency virus (HIV)-related disease. The neurodegenerative processes in HIV infection result in neurocognitive decline, which range in severity from asymptomatic neurocognitive impairment to minor neurocognitive disorder and to HIV-associated dementia (HAD). There have been changes in the definitions during the last decade that evolved to the current term used for these conditions, ie, HIV-associated neurocognitive disorders (HAND). The precise pathogenesis of neurodegeneration associated with HIV infection is still unclear. However, neurons are the final targets of the neurodegenerative process, and additional cells are involved as well. The concomitant damaged substrate exhibits brain inflammation that is associated with HIV infection, ie, HIV encephalitis (HIVE), and can also involve macrophage/microglial infiltration and astrocytosis. ${ }^{1-5}$ Although 
the incidence of HAND has decreased due to combination antiretroviral therapy and other treatments, in recent years the prevalence of HAND has actually increased. Several factors are responsible for this trend, including side effects of combination antiretroviral therapy, increased longevity of patients, and viral mutations including drug resistance. ${ }^{5-10}$ The importance of psychiatric symptoms, including anxiety and depression, are relevant as well because they are components of the stressors to which the brain is subject. $2,6,10,11$ Tissues from the cases utilized here derive from the period prior to the advent of HAND classifications and reflect earlier work.

Several studies of gene expression in culture and in postmortem brain tissue relate to gene expression in patients who died with HIVE and HAND and have been reviewed. 5,12-19 Most brain studies analyzed RNA purified from small aliquots of brain tissue dissected from postmortem specimens. One such study, for example, utilized the frontal cortex from five subjects infected with HIV-1 and four controls negative for HIV-1 using microarrays. These two groups were analyzed by K-means cluster analysis. Genes with perturbed expression were identified that included cell cycle, inducible nitric oxide, chemokine, splicing, synapse, ribosomal proteins, maltose binding protein, myelin proteolipid protein, N-methyl-D-aspartic acid receptor, myelin-associated glycoprotein, astrocytic protein, Notch 3, amyloid precursor protein, senescence, proteasome, ferritin, and signaling. ${ }^{20}$ In related work, IFN- $\gamma$ showed increased expression in brain tissue from patients who died with NeuroAIDS and drug abuse compared with controls, while other cytokines did not show elevation. ${ }^{21}$ In another study, gene expression in gray matter from the frontal lobe was analyzed using microarrays comparing cases with HIVE versus control cases without HIVE. This study indicated that HIV-1 infection in brain tissue associated with HIVE resulted in neurodegeneration and interfered with genes that regulate the cytoskeleton, synaptic-dendritic integrity and function, and signaling, and induced a neuroinflammatory response. Seventy-four genes were downregulated and 59 genes were upregulated. Downregulated genes had functions related to signaling (phosphatidylinositol-3-kinase, Ras-Raf-MEK1), transcription, cytoskeleton (MAP-1B, MAP-2, tubulin, adducin-2), the cell cycle (p35, p39, CDC-L2, CDC42, PAK1), synaptic plasticity, and synaptic transmission (ion channels, synaptogyrin, synapsin II). Upregulated genes had functions related to signaling modulation (MEK3, EphB1), cytoskeleton (myosin, aduccin-3, radixin, and dystrobrevin), transcription (STAT1, OLIG2, Pax-6), neuroimmune response (immunoglobulin G, major histocompatibility complex, $\beta_{2}$-microglobulin) and antiviral response (interferon inducible). ${ }^{22}$

Gene expression profiles related to astrocytes were shown to have many similarities across differing brain tissues (from patients with HIV-1 dementia and from macaques infected with simian immunodeficiency virus) and included several human and murine astrocyte cell culture systems. The use of astrocyte culture systems in the study of NeuroAIDS is supported because of the similarity of gene expression profiles in brain tissue and cultured cells and because astrocytes constitute a large percentage of cells in brain tissue. Several in vitro studies utilized HIV-1 and HIV-1 proteins, ie, Tat, envelope glycoprotein gp120, or negative regulatory factor. The correspondence of gene expression perturbed in these systems and in the brain includes cytokines, chemokines, and their receptors, and is also consistent with astrocyte activation. $^{23,24}$

Neuronal cell cultures are also model systems. For example, a neuronal culture model of the dysfunctional NeuroAIDS brain including drug abuse utilized eight treatment conditions $(2 \times 2 \times 2)$, with and without each of cocaine, Tat, and envelope protein. Statistically significant perturbation of gene expression was demonstrated for 35 genes across all treatment conditions using one-way analysis of variance. Functions of these genes included signaling, immune-related functioning, and transcription control. $^{25}$

Human brain cortex middle frontal gyrus gene expression profiles were compared for cases of HAD or milder cognitive dysfunction versus HIV-negative cases. This work focused on neuronal dysfunction and possible relationships with subcortical dementia. Genes studied were ionic conductance carriers that control membrane excitation. Overexpressed genes included calcium-driven $\mathrm{K}^{+}$channel, leak type of $\mathrm{K}^{+}$ channel, adenosine receptor, serotonin receptor, and the gamma aminobutyric acid receptor subunit. Underexpressed genes included two voltage-gated $\mathrm{K}^{+}$channels, a $\mathrm{Na}^{+}$ channel subunit, a neuronal type of voltage-sensitive $\mathrm{Ca}^{2+}$ channel, a metabotropic glutamate receptor, and the N-methyl-D-aspartic acid receptor subunit. Although unfractionated tissue was used, the perturbed gene expression was considered to stem from neurons because changed expression of these genes changes did not occur in gyral white matter and were not associated with overall changes in glial markers. Moreover, these changes occurred with HAD, with and without HIVE, and were not associated with increased inflammatory gene expression. ${ }^{26,27}$ The Trojan horse model predicts that $\mathrm{HIV}-1$-infected monocytes are a risk for brain penetration of 
HIV-1 via monocyte trafficking into the brain. ${ }^{28}$ Surface gene expression associated with such cells included CD14, CD68, CD14a, and HLA-DR. ${ }^{29}$ Pulliam et al studied gene expression on CD14+ monocytes from HIV-infected cases. Cases with high virus load showed increased expression of sialoadhesin, CD16, CCR5, and MCP-1. However, proinflammatory cytokine gene expression (interleukin-1, interleukin-6, and tumor necrosis factor- $\alpha$ ) was unchanged. ${ }^{30}$

Microarray analysis in a monkey model using frontal lobe tissue from simian immunodeficiency virus-infected brains identified 98 genes with altered expression. Genes expressed were associated with promoting macrophage entry into the brain and associated toxic products. Those significantly upregulated included proteins in infiltrating macrophages, endothelial cells, and resident glia (eg, CD163, Glut5, and ISG15). Proteins found in cortical neurons included cyclin D3, tissue transglutaminase, $\alpha 1$-antichymotrypsin, and STAT1. ${ }^{31}$

Laser capture microdissection has been used successfully in the study of several human brain diseases, including the HIV-1-infected brain, subacute sclerosing panencephalitis, Parkinson's disease, and Huntington's disease. ${ }^{32-39}$ In the current study, only cases with HAD and HIVE (as well as HIV-1-positive controls) were used. Thus, work in NeuroAIDS has progressed to the point where cell-specific studies will be able to elucidate additional information using novel approaches. We report on gene expression in specific neuroanatomically defined neurons.

\section{Materials and methods}

\section{Brain tissue}

As previously described, ${ }^{39}$ autopsied cryopreserved brain tissue was obtained from the National Institutes of Health-sponsored National NeuroAIDS Tissue Consortium sites $^{40,41}$ (Table 1). At each of the National NeuroAIDS Tissue Consortium sites, the diagnosis of HIV-1-positive individuals with and without HAD and HIVE was made based on premortem neurological and clinical neuropsychological examination of the patients and at postmortem by neuropathological examination. Each subject was given a diagnosis, using a standardized, algorithmic diagnostic worksheet to combine neurological, neuropsychological, functional, and laboratory information. Postmortem tissues were examined by board-certified neuropathologists to exclude subjects with opportunistic central nervous system infections, tumors, or other causes of dementia, such as Alzheimer's disease. Furthermore, most subjects were below the age at which a dementing neurodegenerative illness would be expected. ${ }^{7,8,11-13,42}$ Tissue was dissected from the globus pallidus and embedded in optimal cutting temperature compound. Sections 10 microns thick were cut using a cryostat at $-23^{\circ} \mathrm{C}$. The cryosections were mounted on laser capture microdissection slides (Microoptics of Florida, Palm Beach, FL). Prior to laser capture microdissection, the slides were cryopreserved at $-80^{\circ} \mathrm{C}$ in sealed Bakelite slide boxes containing drierite. ${ }^{39}$

Table I Patient demographics and diagnosis

\begin{tabular}{|c|c|c|c|c|c|c|c|c|}
\hline Subject number & HAD & HIVE & Gender & Race & Ethnicity Hisp & Risk & $\begin{array}{l}\text { Duration HIV } \\
\text { infection } Y\end{array}$ & Age at death $Y$ \\
\hline I & + & + & M & Cauc & - & MSM & 17 & 47.30 \\
\hline 2 & + & + & M & Cauc & + & MSM & 4 & 44.13 \\
\hline 3 & + & + & M & Black & - & MSM & 10 & 43.53 \\
\hline 4 & + & + & M & Cauc & - & MSM & 3 & 35.42 \\
\hline 5 & + & - & $\mathrm{F}$ & Black & - & IDU & 7 & 64.96 \\
\hline 6 & + & - & $\mathrm{F}$ & Cauc & - & BPR HS & 3 & 58.27 \\
\hline 7 & + & - & M & Cauc & - & IDU & 13 & 62.48 \\
\hline 8 & - & + & M & Cauc & + & HS IDU & 12 & 33.10 \\
\hline 9 & - & + & M & Black & - & BPR HS MSM & 12 & 46.75 \\
\hline 10 & - & - & M & Cauc & + & MSM & 10 & 50.14 \\
\hline II & - & - & $M$ & $\mathrm{NaAl}$ & - & MSM & 15 & $42.4 I$ \\
\hline 12 & - & - & $M$ & Cauc & - & MSM & 15 & 46.16 \\
\hline 13 & - & - & $M$ & Cauc & + & MSM & 8 & 34.65 \\
\hline 14 & - & - & $M$ & Cauc & - & MSM & $U$ & 54.35 \\
\hline 15 & - & - & $M$ & Cauc & - & $\mathrm{U}$ & 23 & 39 \\
\hline 16 & - & - & $M$ & Cauc & - & $U$ & 12 & 64.69 \\
\hline
\end{tabular}

Notes: All patients HIV-positive; all tissues from globus pallidus; +, present; -, absent.

Abbreviations: HAD, HIV-associated dementia; HIVE, HIV encephalitis; Cauc, Caucasian; Hisp, Hispanic; NaAl, native Alaskan; Y, years; IDU, injection drug abuser; $\mathrm{U}$, unknown; HS, heterosexual; MSM, men who have sex with men; BPR, blood product recipient (blood transfusion); Y, years. 


\section{Laser capture microdissection}

Slides for laser capture microdissection were lightly stained with Nissl (Arcturus Inc, Mountain View, CA) and dehydrated using an ethanol series followed by xylenes as previously described. ${ }^{39} \mathrm{~A}$ Leica laser microdissection microscope (Leica Corporation, Bannockburn, IL) was used for laser capture microdissection using standardized settings and the laser beam precisely followed the neuron's outer membrane. Only neurons with nucleoli were microdissected. No other cells had nucleoli. ${ }^{39}$

\section{RNA purification}

For each case and control tissue, batches of 200 microdissected single cell neurons were suspended in $20 \mu \mathrm{L}$ of extraction buffer (Picopure RNA extraction kit, Arcturus Inc) and RNA was extracted. The batches were pooled from multiple cryosections of each tissue. A CapSure-ExtractureSure assembly incubation block with cover (Arcturus Inc) was used to house the tubes. The block was incubated for 30 minutes at $42^{\circ} \mathrm{C}$ to extract the RNA. The RNA was cryofrozen on dry ice and stored under liquid nitrogen. ${ }^{39}$

\section{Gene expression analysis}

Biotin-labeled cRNA was prepared by linear amplification of the poly (A)+ RNA population within the total RNA sample. Briefly, about $0.5 \mathrm{ng}$ of total RNA (estimated by the number of cryosectioned cells used for RNA isolation) was amplified using a RiboAmp HS kit (Arcturus). After second-strand cDNA synthesis and purification of double-stranded cDNA, in vitro transcription was performed using T7 RNA polymerase in the presence of biotinylated uridine- 5 '-triphosphate. It must be noted as crucial in the method, that the quantity and quality of the cRNA were assayed by spectrophotometry followed by analysis on an Agilent Bioanalyzer (Agilent Technologies, Colorado Springs, CO). The quality of the cRNA is paramount to ensure nonbiased representation of labeled transcripts containing the complement of the probe sequences deposited on the array. ${ }^{39}$

Ten micrograms of purified cRNA were fragmented to uniform size and applied to CodeLink Human Whole Genome Bioarrays (GE Healthcare, manufacturer instructions) in hybridization buffer. The specifications, use, and descriptions of the GenUS BIOSYSTEMS CodeLink human CHIPS were as described previously. ${ }^{43,44}$ CodeLink Human Whole Genome arrays comprise approximately 55,000 30-mer probes designed to probe conserved exons across the transcripts of targeted genes. These probes represent annotated, full length, and partial human gene sequences from major public databases.
All fragmented samples were visualized on the Agilent Bioanalyzer to verify complete fragmentation to about 0.1 $\mathrm{kb}$ size before array analysis. Arrays were hybridized at $37^{\circ} \mathrm{C}$ for 18 hours in a shaking incubator, washed in $0.75 \times$ tris sodium chloride EDTA (TNE) at $46^{\circ} \mathrm{C}$ for 1 hour, and stained for 30 minutes with $\mathrm{Cy} 5$-streptavidin dye conjugate. Arrays were then rinsed, dried, and scanned at $5 \mu \mathrm{m}$ resolution with a GenePix ${ }^{\text {TM }}$ 4000B scanner (Axon Instruments, according to manufacturer instructions and software).

\section{Statistical analysis \\ Data production}

CodeLink Expression Analysis software (GE Healthcare) was used to process the scanned images from arrays (gridding and feature intensity) and the data generated for each feature on the array were analyzed using GeneSpring software (Agilent Technologies). All control genes and genes that did not pass the quality control metrics of the manufacturer were removed from further analysis. ${ }^{44}$

To compare individual expression values across arrays, raw intensity data from each gene were normalized to the median intensity of the array. Only genes with values greater than background intensity in at least one treatment condition were used for further analysis. Using a ratio interpretation of the data and normalization of each gene to the median intensity across conditions, data were filtered by expression intensity for genes that did not vary by $50 \%$ across all samples within the experiment. These unchanging genes were also eliminated from further analysis. This set of present genes was filtered for genes that were within one standard deviation from the mean of replicates. The remaining qualified gene list was queried for genes in treated groups that had ratios $>2.0$ and $<0.5$ (two-fold changes) relative to controls. Gene identification based on the GE identifiers was further accomplished using standard websites. ${ }^{43-46}$

\section{Statistical methods}

The data from this two-way unbalanced cross-classification experiment were analyzed first using analysis of variance to find genes that were statistically significantly different among the four groups at $P \leq 0.005$. Following the analysis of variance, pairwise Student $t$-tests were performed using the mean square error from the analysis of variance to test the simple effects of $\left(\mathrm{HAD}^{+} \mathrm{HIVE}^{+}\right)$versus $\mathrm{HIV}^{+}$control, $\left(\mathrm{HAD}^{+} \mathrm{HIVE}^{-}\right)$versus $\mathrm{HIV}^{+}$control, and $\left(\mathrm{HAD}^{-} \mathrm{HIVE}^{+}\right)$ versus $\mathrm{HIV}^{+}$control for each selected gene. These pairwise comparisons were used to find the simple effects giving 
rise to the overall statistically significant difference among the four groups. Doing the pairwise comparisons this way is based on Fisher's least significant difference test, which is done only if the overall $F$-test is significant. Using this approach, the pairwise tests do not need to be adjusted for multiple comparisons because the experiment-wise error rate is controlled by the $F$-test.

\section{Pathway analysis}

Pathway figures and gene interactions were generated using Gene Network Central PRO. ${ }^{47}$ Pathways were also analyzed using Ariadne Pathways Assist. ${ }^{48}$

\section{Results}

\section{Gene expression changes}

Sixteen globus pallidus specimens were used as a single experiment (Table 1). The means and standard errors of 197 genes are shown in Table 2. Of these genes, 150 were identified from the GE CodeLink, NCBI, and GeneCards websites. Table 2 also shows the $P$ values for overall and simple effects. Three gene expression comparisons made were HAD with HIVE, HAD alone, and HIVE alone, each versus $\mathrm{HIV}^{+}$infected controls. Of the identified genes, HAD with HIVE versus $\mathrm{HIV}^{+}$showed 27 genes upregulated and 30 genes downregulated. HAD alone versus $\mathrm{HIV}^{+}$showed 108 genes upregulated and 22 downregulated. HIVE alone versus $\mathrm{HIV}^{+}$showed 65 genes upregulated and 33 genes downregulated. In all three comparisons, three genes showed simultaneous upregulation and three genes showed simultaneous downregulation. In addition, comparing HAD/HIVE, HAD alone, and HIVE alone versus $\mathrm{HIV}^{+}$, the following gene expression shifts, respectively, were one up-up-down, updown-up, down-up-up, up-down-down, two down-down-up, and three down-up-down (Table 2). The triply regulated genes were as follows: up-up-up, B3GALT1 (galactose transferase), FLJ14167 (potassium inwardly-rectifying channel), and an unidentified gene; up-up-down, NYD-SP26 (development), up-down-up, SLC44A5 (choline transporter-like protein 5), down-up-up, one gene unidentified; down-down-down, HoxD11/HoxD10 (transcription factor, homeobox-regulated development), TBC1D22A (GTPase activator); downdown-up, one gene unidentified, HNRPA1P5 (heterogeneous nuclear ribonucleoprotein A1 pseudogene 5); down-up-down, one gene unidentified, DNAJC3 (chaperone, interferoninduced, double-stranded RNA-activated protein kinase inhibitor), SLAMF6 (SLAM family member 6, CD2 surface receptor, membrane component); and up-down-down, SLC36A4 (amino acid transporter).

\section{Gene expression groups}

The identified genes and their functions are shown in Table 3. There are large numbers of functions and gene groups because many genes are in more than one group. The categories of these functions include adhesion cell, adhesion matrix, adhesion membrane, amyloid beta synthesis, amyloid beta precursor processing, apoptosis, apoptosis caspase activator, binding metal ion, binding nucleotide, binding GTP, binding heparin, binding phosphatidyl inositol, binding DNA, binding RNA, binding double-stranded RNA, biosynthesis, biosynthesis amino acid, channel complex $\mathrm{Ca}$, cell cycle, cell differentiation, cell division, cell division arrest, channel potassium inward rectifier, chaperone, chaperone cochaperone, chromatin regulation assembly, chromatin regulation repair, collagen, cytokine, cytokine growth factor, cytoskeleton, microtubule, development nervous system, developmental protein, Alzheimer's disease, diGeorge syndrome, Huntington's disease, DNA polymerase, DNA repair, endoplasmic reticulum, endocytosis, esterase thio-acyl-CoA, exocytosis, factor viability, glutamate polyglutamylase, glutamyl transferase, glycan N-glycan processing, glycosylation N-linked, glycosylation O-linked, Golgi stack apparatus, Golgi clathrin coat, Golgi vesicle, G protein cycle, GTPase, heat shock, hydrogenase-like protein iron only, interferon induced pathway, lamin prelamin recognition factor, lamin prelamin binding protein, lamina nuclear, lipid biosynthesis, lipid phosphatidyl serine biosynthesis, lipid phospholipid biosynthesis, matrix cell, matrix extracellular, metabolism, mitochondrial electron transport, mitochondrial function, mitochondrial membrane, mitochondrial metalloproteinase protein, mitochondrial ribosomal protein, mitochondrial ribosome, motility cell, movement intracellular, mRNA transport, multinetwork protein, multinetwork detection protein or RNA, nucleopore, nucleopore mRNA transport, oligosaccharide biosynthesis, oligosaccharide hydrolase, oncogene, oxireductase, oxidase, peptidase, peptide crosslinking, perception sensory olfactory, perception sensory visual, proliferation cell, protease, protease endoprotease, protein biosynthesis, protein kinase, protein phosphatase, proteinase metallo, pseudogene, receptor AMPA, receptor cytokine, receptor cytokine ligand, receptor interacting protein, receptor NMDA, receptor glutamate, receptor glycophorin, receptor metabotropic, receptor nuclear interacting, receptor MHC class I, receptor MHC class I antigen presentation, ribosome, ribosome subunits, ribosome assembly, ribosome protein, ribosome protein synthesis, ribosome translation factor, ribosome translation initiation factor, RNA heterogeneous nucleoprotein, RNA noncoding, RNA miRNA, signaling ras 


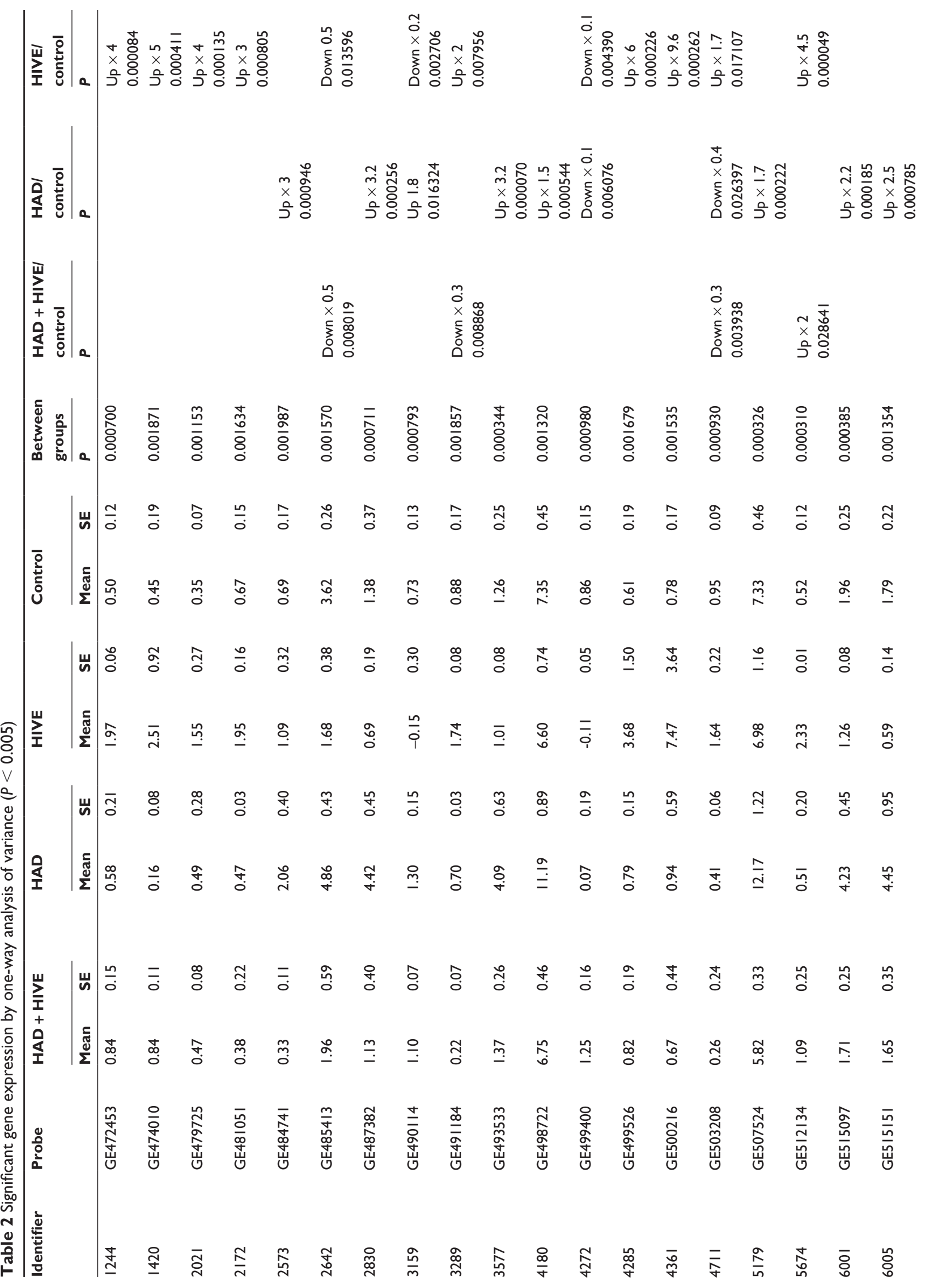




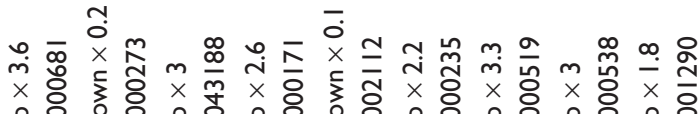

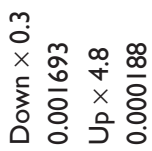

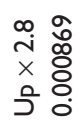

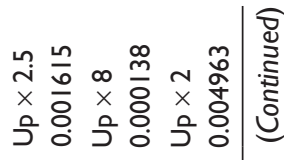

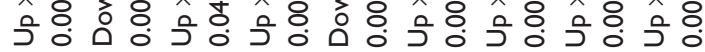

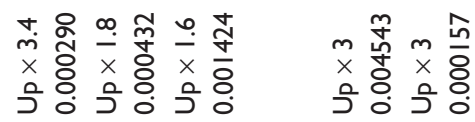

$\overline{0}$
$\times$
5
$\xi$
$\vdots$
0
0
0

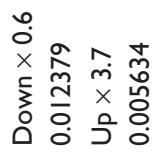

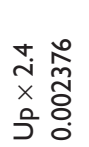

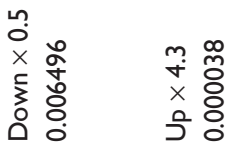

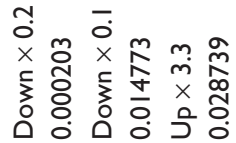

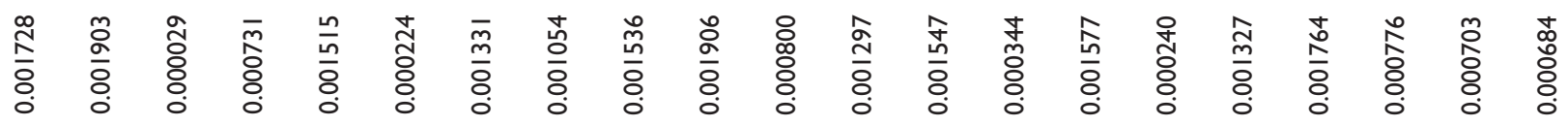

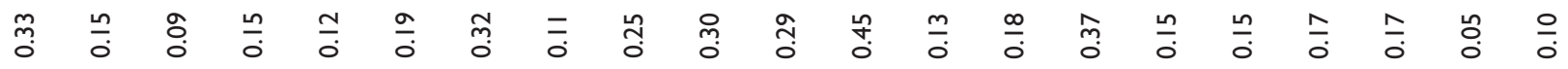

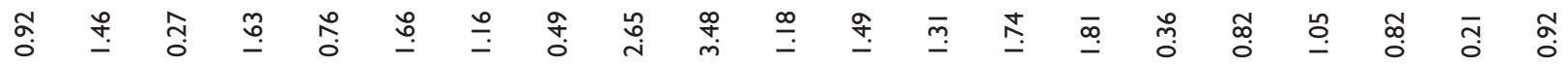

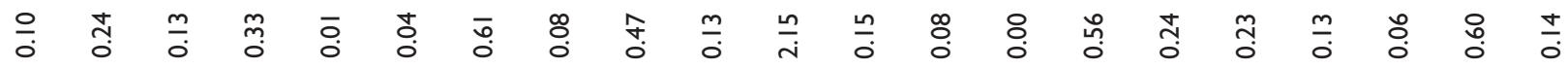

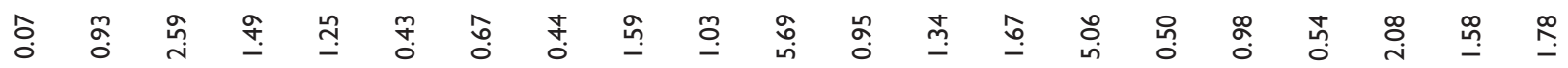

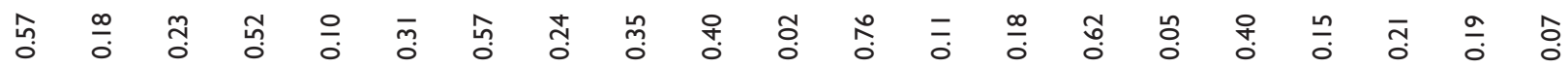

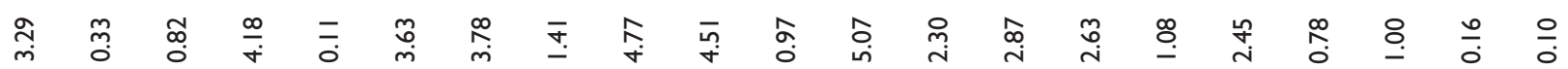

숭

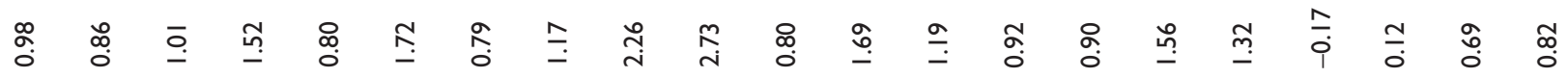

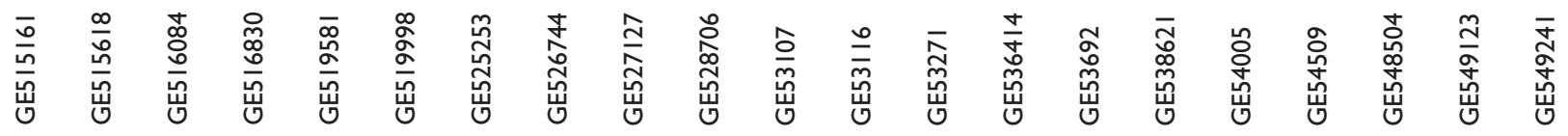

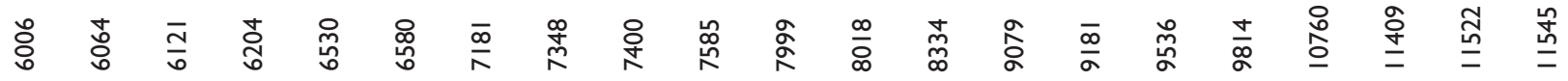




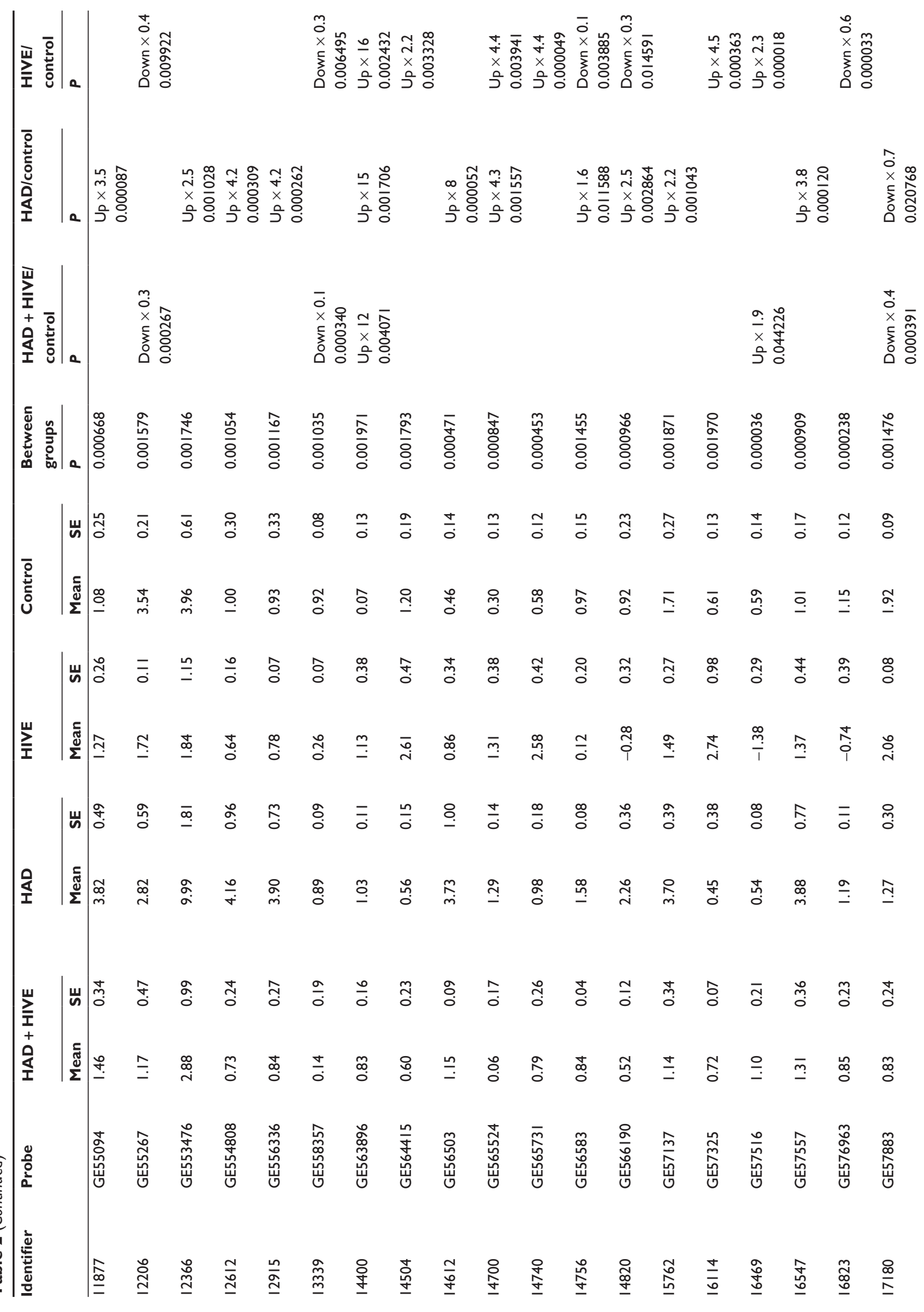




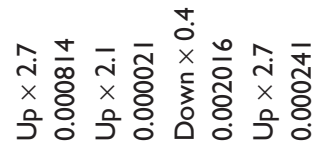

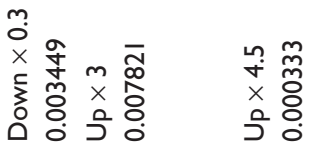

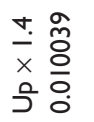
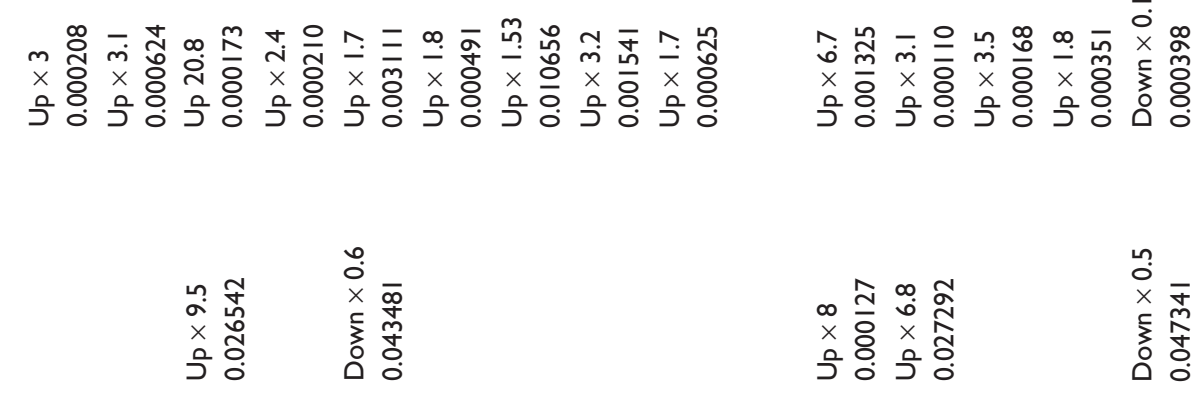

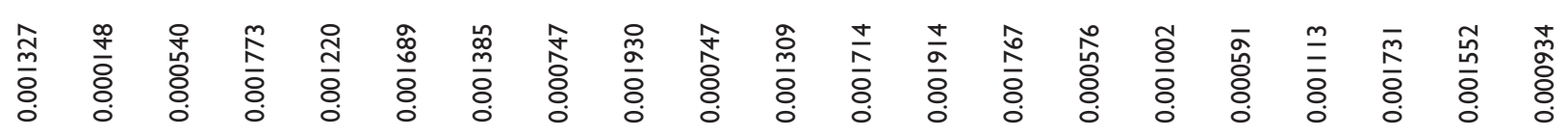

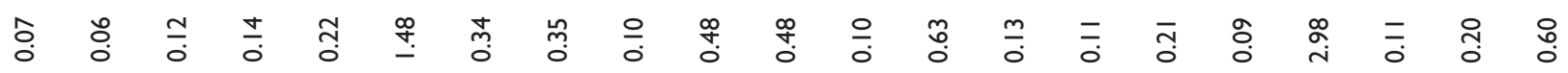

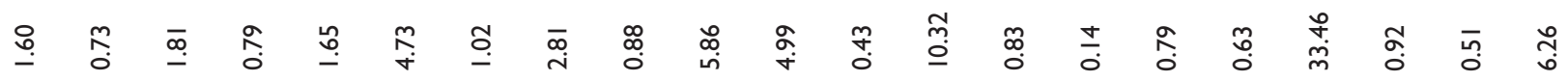

志 웅 응

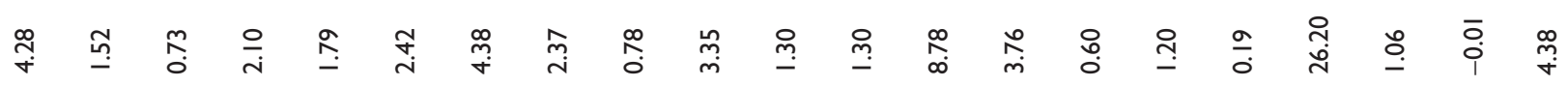

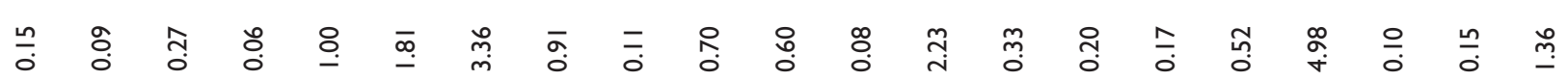

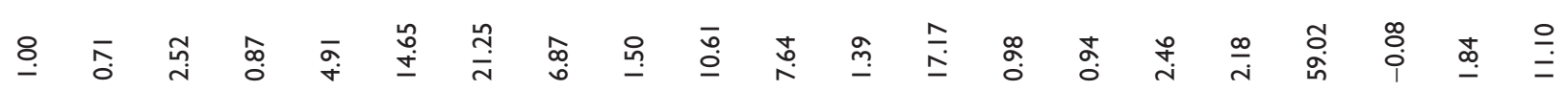

兽

ホ.

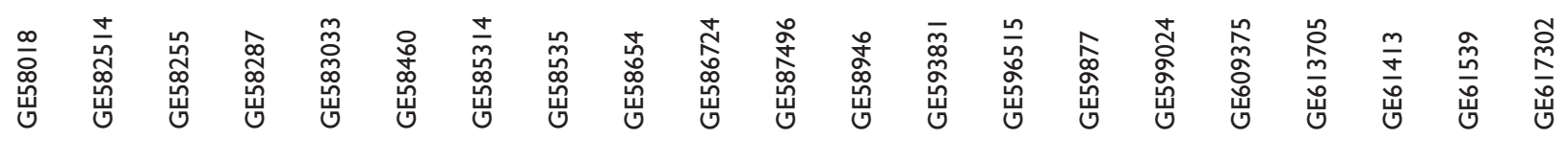

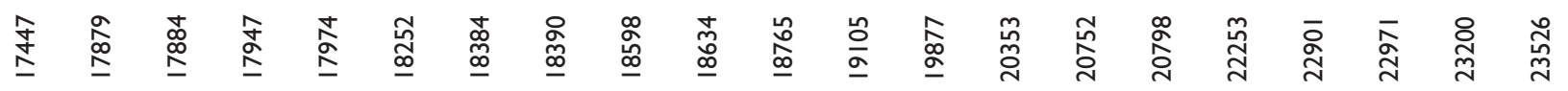




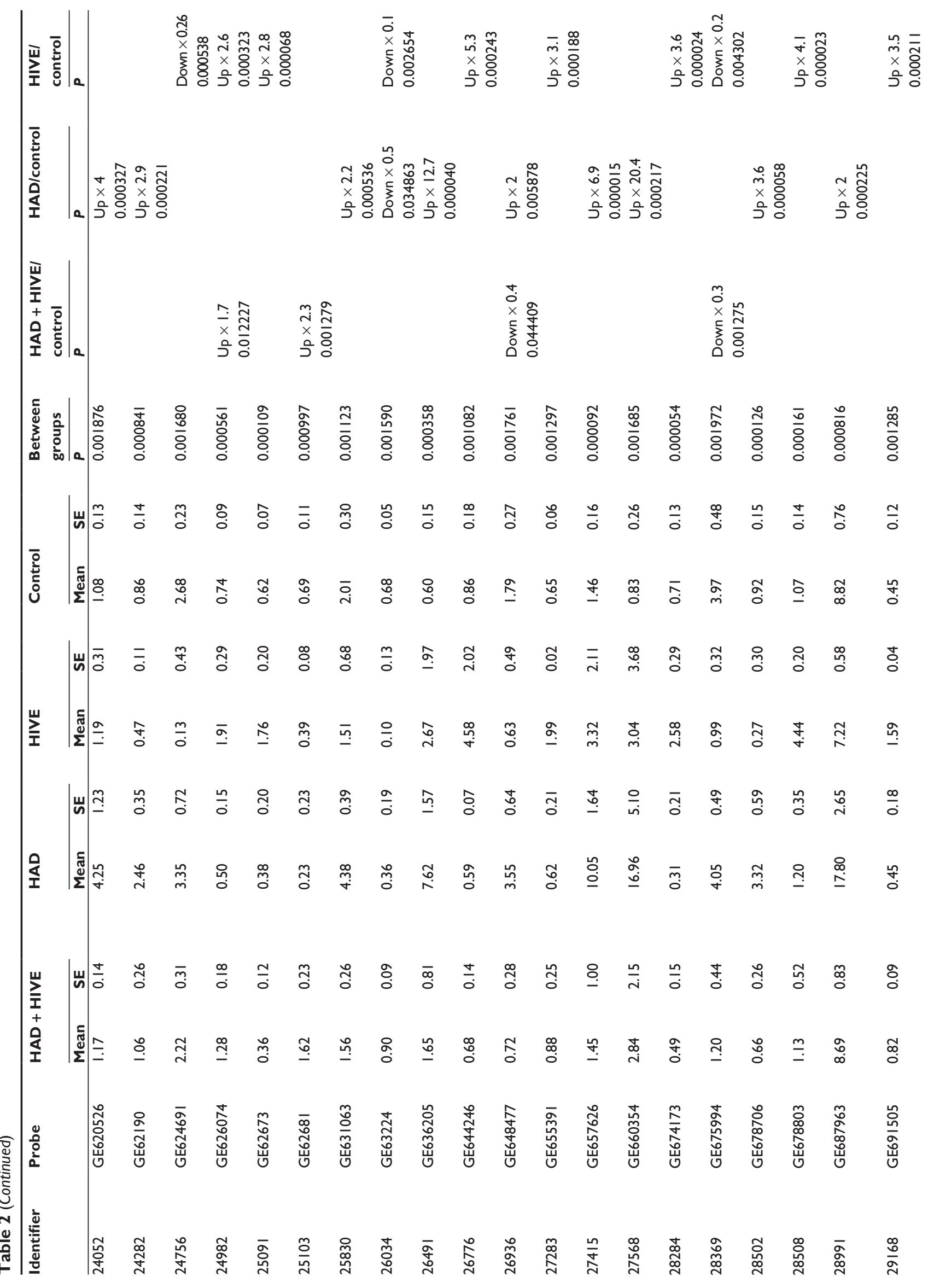




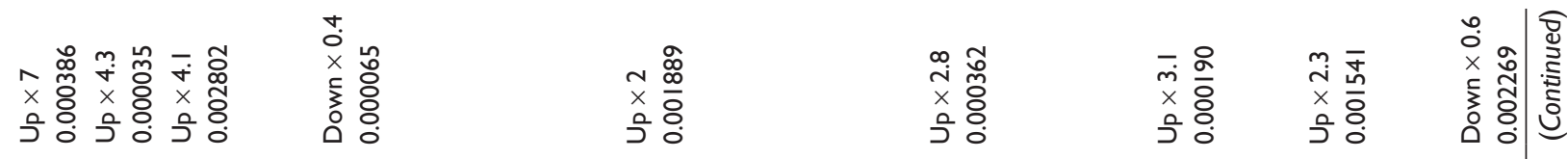

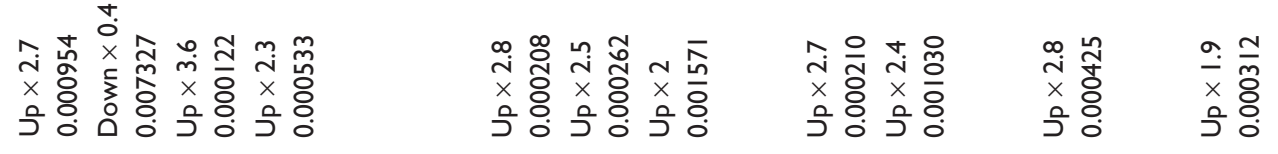

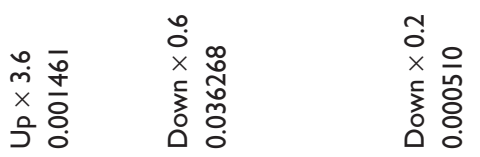

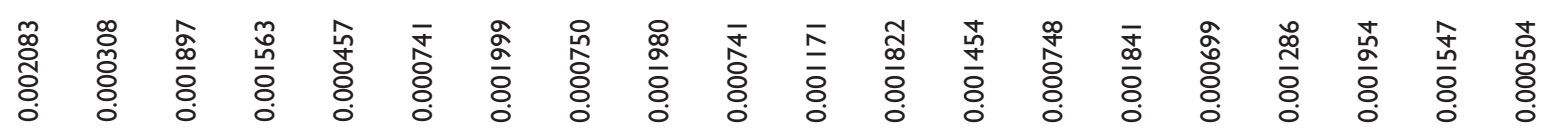

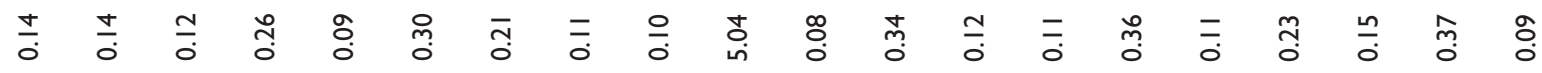

苍

읏

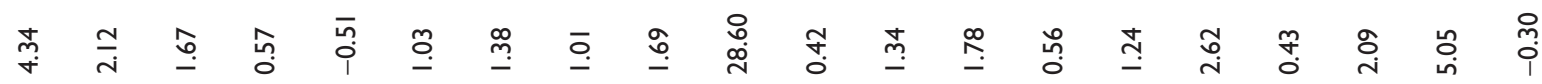

F.

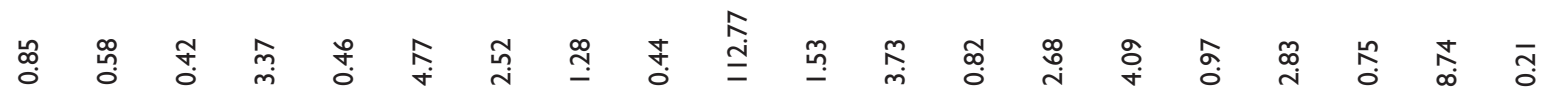

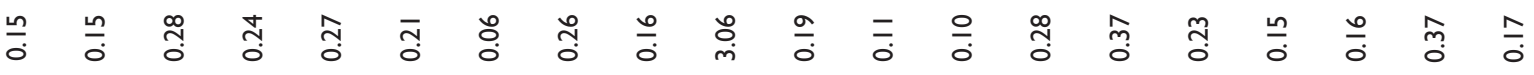

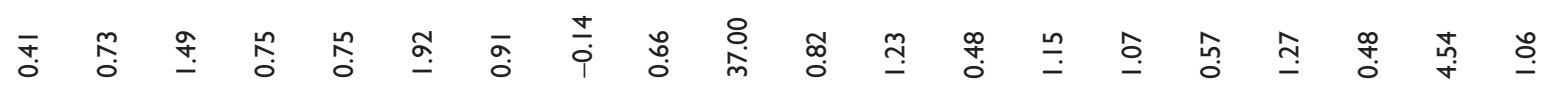

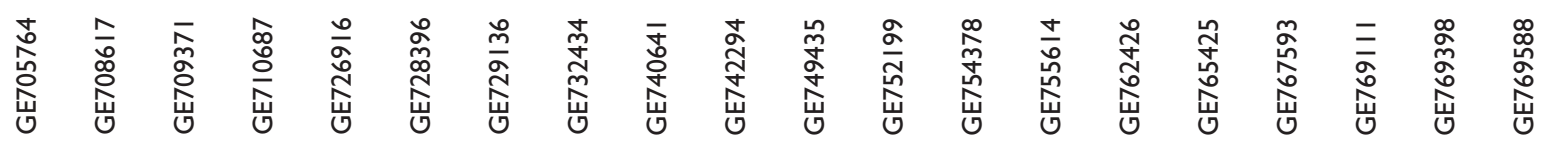

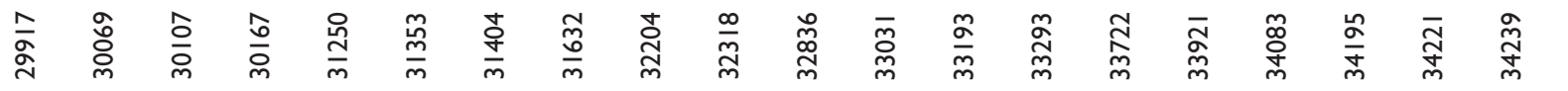




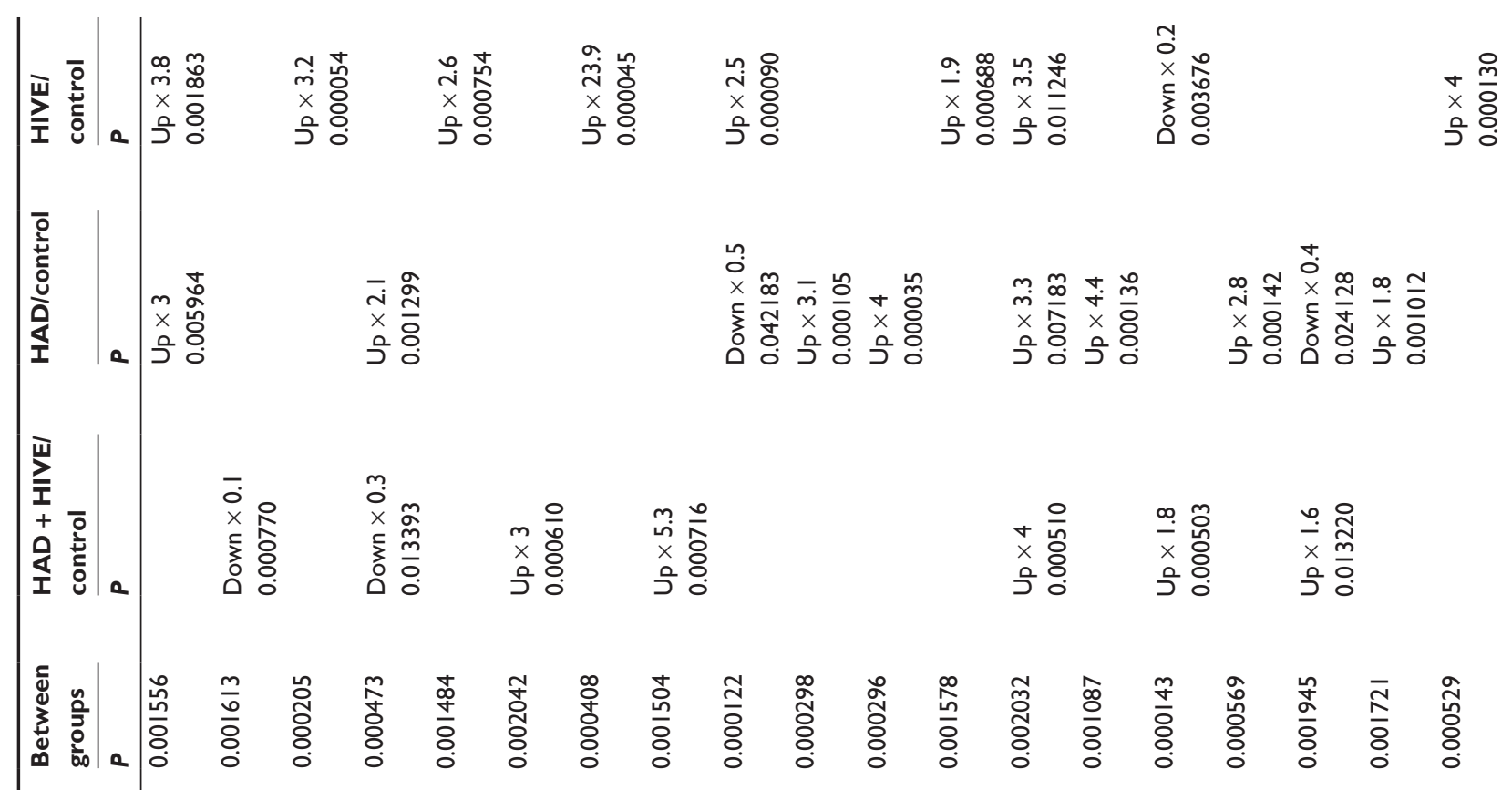

山

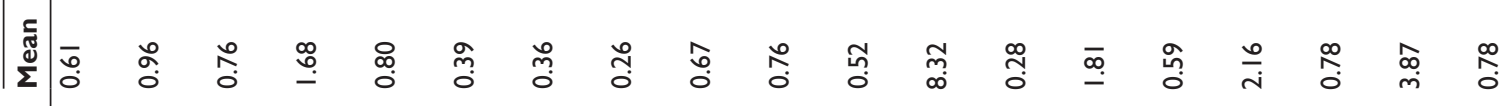

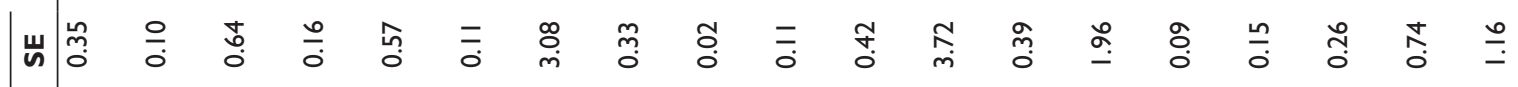

岸

山

余

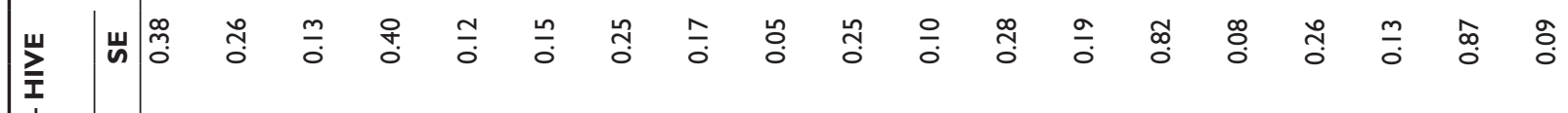

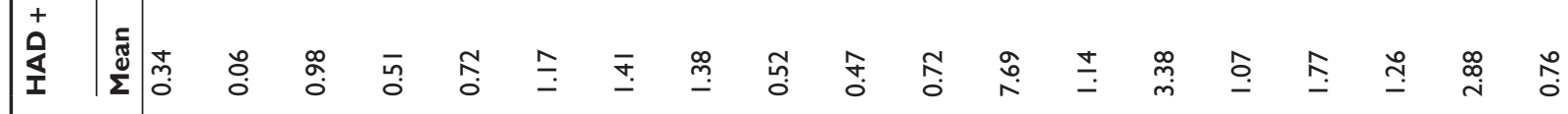

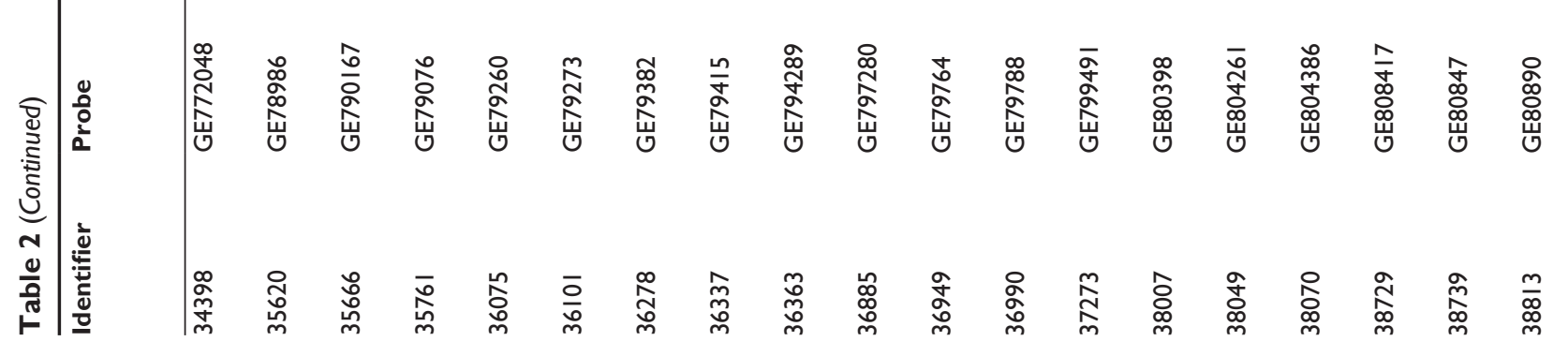




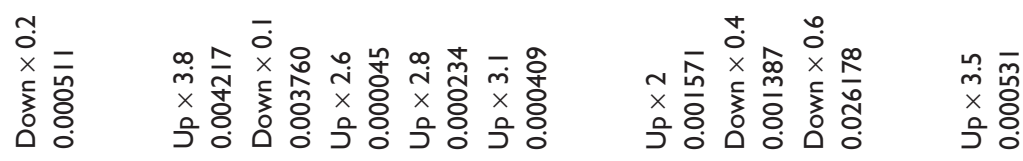

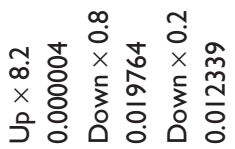

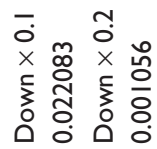

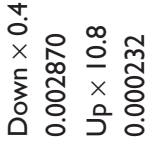

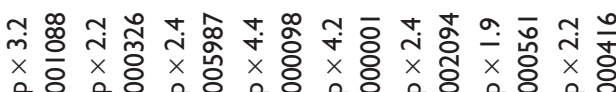

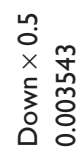

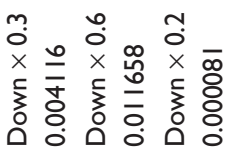

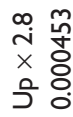

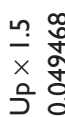

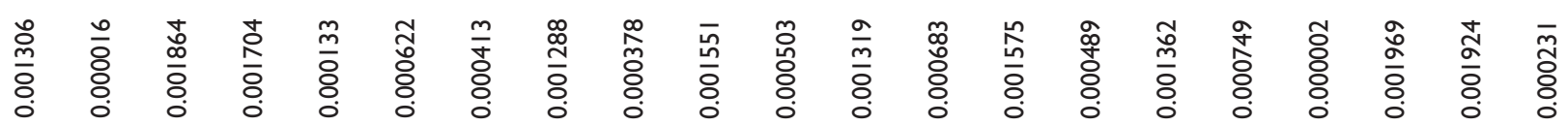

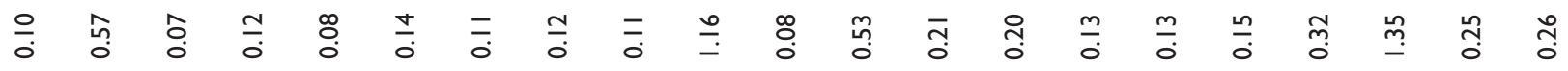

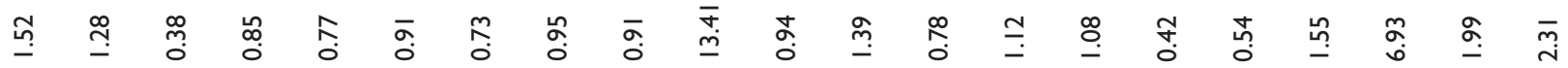

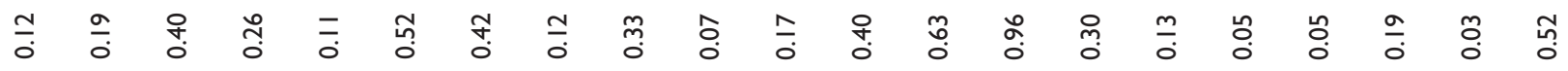

岗 f.

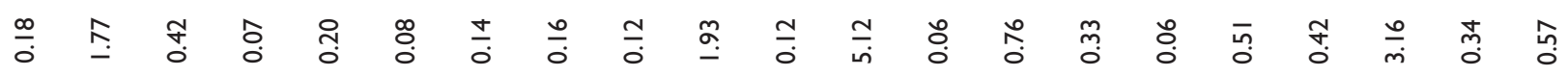

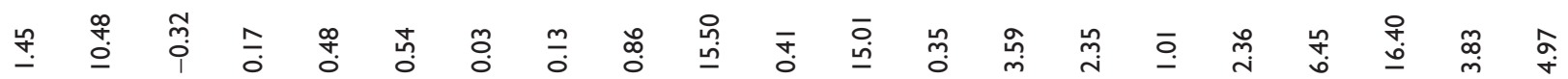

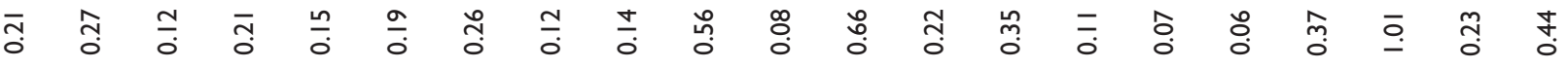

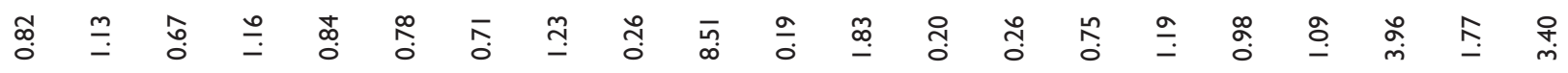

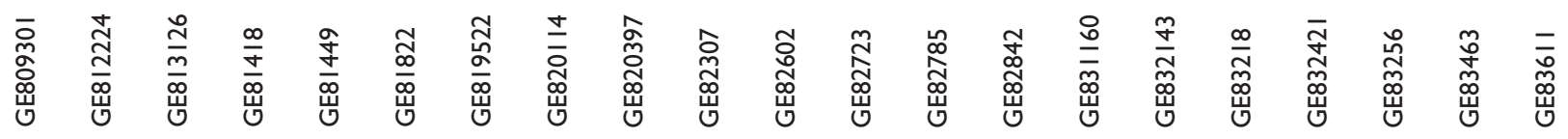

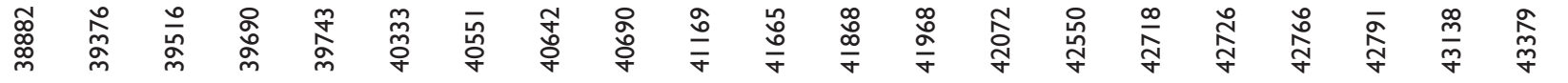




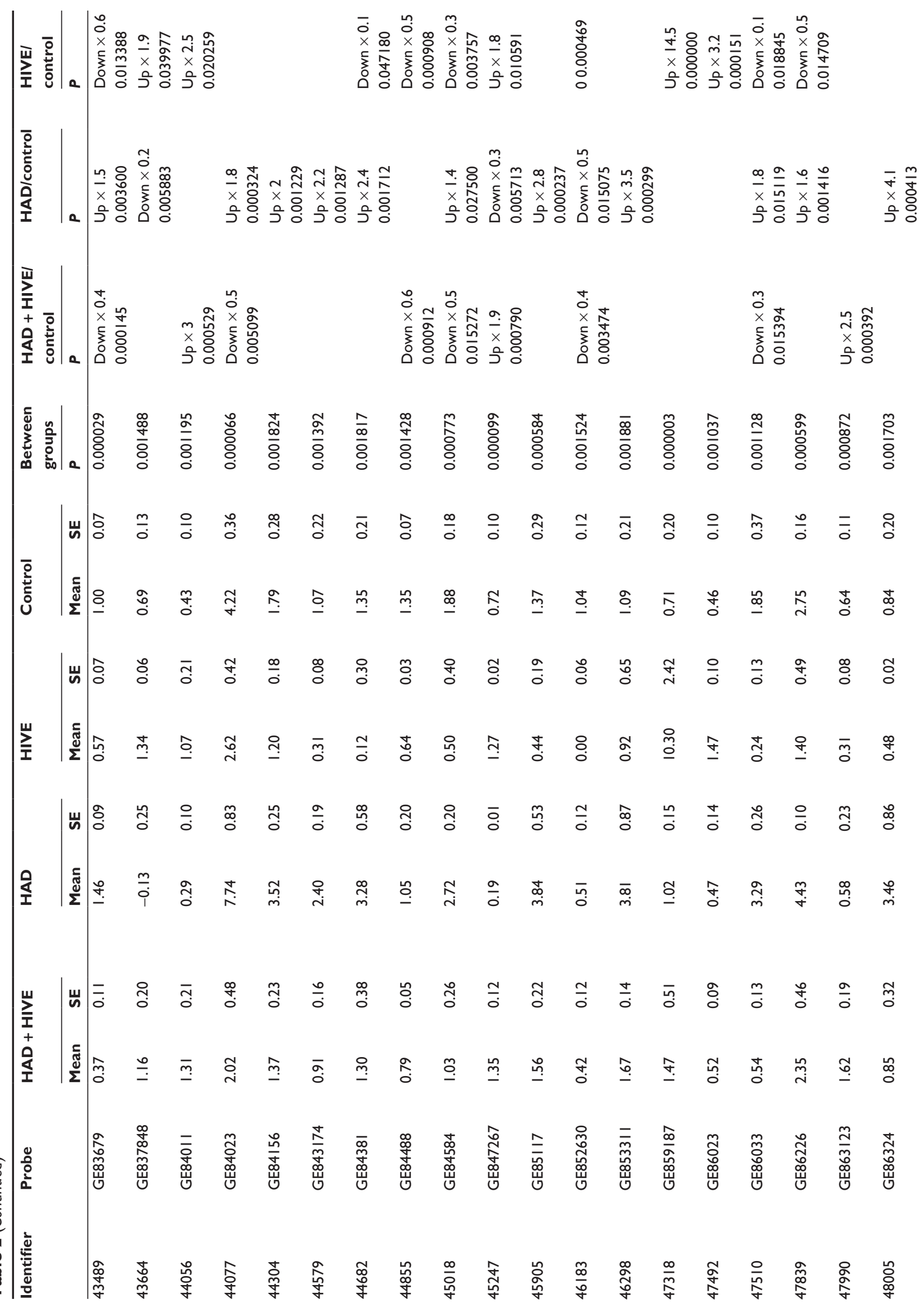




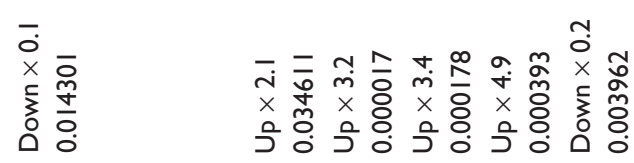

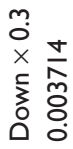

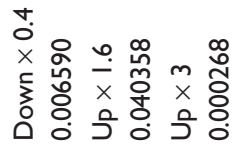

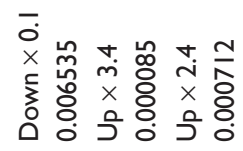

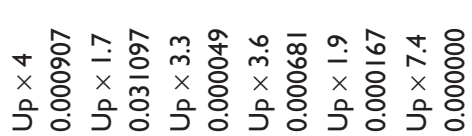

更
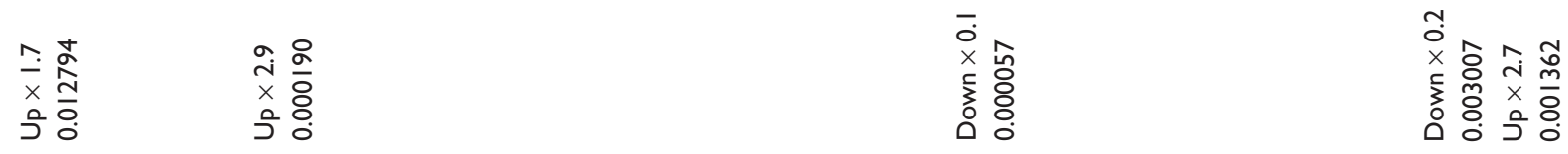

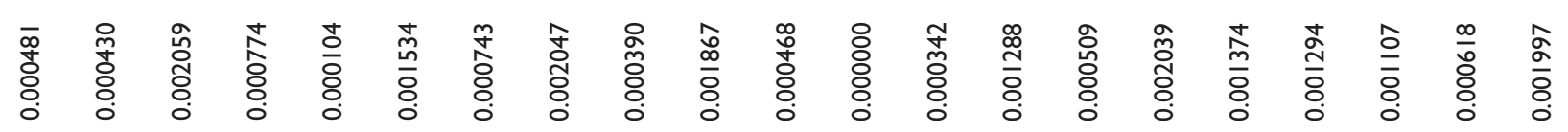

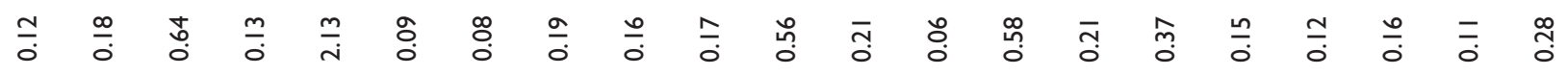



$\frac{m}{\circ}$ 둥

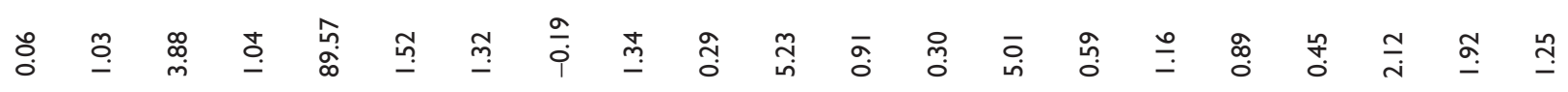

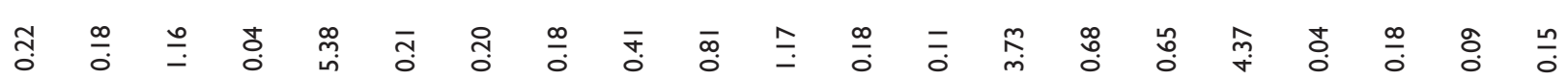

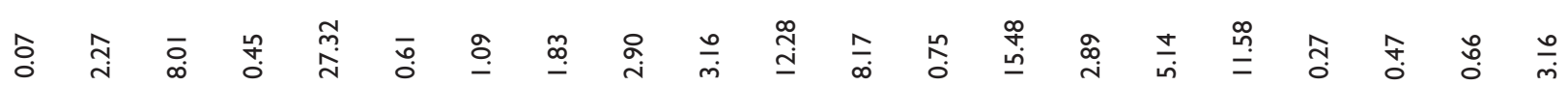

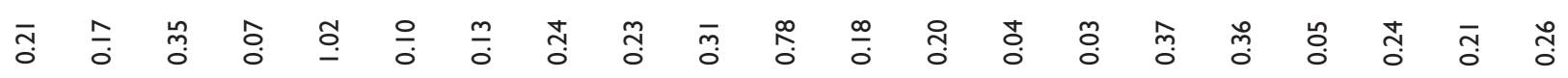

문

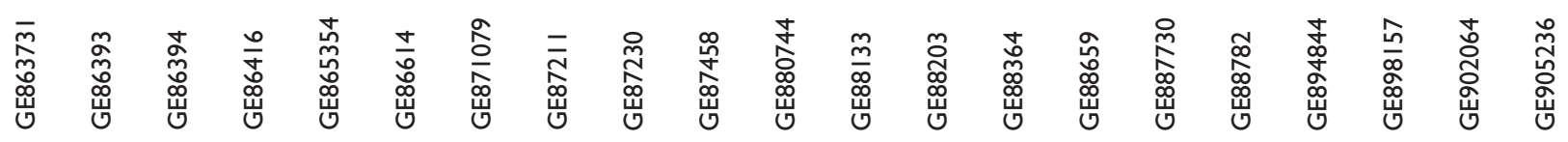

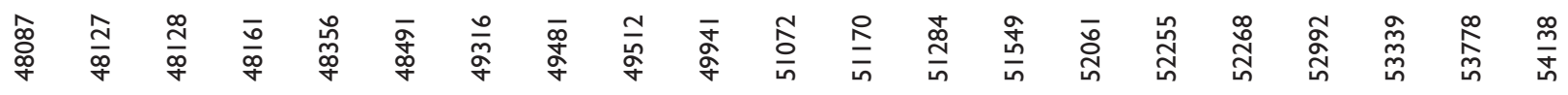


Table 3 Select expressed genes and functions ${ }^{4-46}$

\begin{tabular}{|c|c|c|c|}
\hline Identifier & Probe & Alias & Functions and comments \\
\hline 1244 & GE472453 & 2NbHMSP & Immune activation-like gene in multiple sclerosis. \\
\hline 1420 & GE4740I0 & GRIN2A & Mg ion binding. lon transport. Plasma membrane integral. \\
\hline 2021 & GE479725 & HECW2 & $\begin{array}{l}\text { E3 ubiquitin-protein ligase that mediates ubiquitination of TP73. Acts to stabilize TP73 } \\
\text { and enhance activation of transcription by TP73. }\end{array}$ \\
\hline 2172 & GE48I05। & - & - \\
\hline 2573 & GE48474I & ANKRDII & $\begin{array}{l}\text { Member of a family of ankyrin repeat-containing cofactors that interacts with pl } 60 \text { nuclear } \\
\text { receptor coactivators and inhibits ligand-dependent transcriptional activation. }\end{array}$ \\
\hline 2642 & GE4854I3 & SYPL2 & Transporter activity. Synaptic vesicle integral to membrane. Synaptophysin-like 2. \\
\hline 2830 & GE487382 & - & - \\
\hline 3159 & GE490II4 & - & - \\
\hline 3289 & GE49।I84 & - & - \\
\hline 3577 & GE493533 & - & - \\
\hline 4180 & GE498722 & - & - \\
\hline 4272 & GE499400 & GNAQ & $\begin{array}{l}\text { Nucleotide GTP binding GTPase. Signal transducer. Protein ribosylation. Signal transduction G } \\
\text { protein coupled receptor signaling pathway. Plasma membrane. Cytoplasm heterotrimeric G } \\
\text { protein complex. }\end{array}$ \\
\hline 4285 & GE499526 & - & - \\
\hline 4361 & GE5002I6 & - & - \\
\hline 4711 & GE503208 & - & - \\
\hline 5179 & GE507524 & - & - \\
\hline 5674 & GE5 I 2134 & NR4AI & Nuclear transcription factor. Translocation from nucleus to mitochondria induces apoptosis. \\
\hline 6001 & GE5I5097 & - & - \\
\hline 6005 & GE5I5I5I & PML & $\begin{array}{l}\text { Nuclear transcription factor. Protein ubiquitination ligase complex. } \mathrm{Zn} \text { ion binding. } \\
\text { Promyelocytic leukemia. }\end{array}$ \\
\hline 6006 & GE5I5I6I & MKLNI & Cell motility. Cell matrix adhesion. Signal transduction. Cytoplasmic. \\
\hline 6064 & GE5I56I8 & TAF4B & Nuclear initiation transcription factor. TFIID complex. \\
\hline 6121 & GE5I 6084 & - & - \\
\hline 6204 & GE5I 6830 & - & - \\
\hline 6530 & GE5I958I & TMTC2 & Transmembrane and tetratricopeptide repeat containing 2 . Multipass membrane protein. \\
\hline 6580 & GE5I9998 & - & 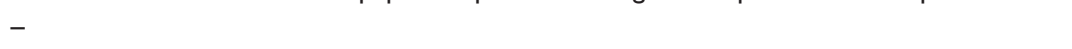 \\
\hline 7181 & GE525253 & FNDC5 & Fibronectin type 3 domain-containing 5. \\
\hline 7348 & GE526744 & APOB & Receptor binding lipid transporter. Heparin binding. Signal transduction. ER microsome. \\
\hline 7400 & GE527I 27 & - & - \\
\hline 7585 & GE528706 & - & - \\
\hline 7999 & GE53107 & BACHI & $\begin{array}{l}\text { Transcription regulation. Nuclear factor. BTB and CNC homology I. Basic leucine } \\
\text { transcription factor I variant I. }\end{array}$ \\
\hline 8018 & GE53II6 & TLK2 & $\begin{array}{l}\text { Nuclear. ATP binding. Serine/threonine kinase. Transferase. Chromatin regulation assembly/ } \\
\text { disassembly. Response to DNA damage stimulus. Tousled-like kinase } 2 .\end{array}$ \\
\hline 8334 & GE5327I & TRAK2/ALS2CR3 & $\begin{array}{l}\text { Receptor binding. Intracellular transporter. Neurotransmitter transport. Cytoplasm. } \\
\text { Plasma membrane. Amyotrophic lateral sclerosis } 2 \text { juvenile. Chromosome candidate region3. }\end{array}$ \\
\hline 9079 & GE5364I4 & ZDHHC5 & Metal ion binding. Membrane integral. Zn finger DHHC-type containing 5. \\
\hline 9181 & GE53692 & B4GALT7 & $\begin{array}{l}\text { Galactosyl transferase. Mn ion binding. Xylosyl-protein. Carbohydrate metabolism. } \\
\text { Proteoglycan metabolism. Protein modification. Golgi stack. Membrane integral. } \\
\text { Xylosyl protein beta I,4-galactosyl transferase polypeptide 7. Galactosyl transferase I. }\end{array}$ \\
\hline 9536 & GE53862I & HISTIH2BC & $\begin{array}{l}\text { Nucleosome assembly. DNA binding. Chromosome organization and biogenesis. } \\
\text { Histone cluster I, H2bc. }\end{array}$ \\
\hline 9814 & GE54005 & CEACAM7 & Plasma membrane integral. Carcinoembryonic antigen-related cell adhesion molecule 7. \\
\hline 10760 & GE54509 & SEC6LI & Exocytosis protein transport. SEC6-like I. \\
\hline 11409 & GE548504 & LOC387856 & Hypothetical protein. Similar to expressed sequence Al836003 (GenBank). \\
\hline 11522 & GE549I 23 & PRRI5 & Hypothetical protein. LOC222I7I. Proline-rich I5 (PRRI5). \\
\hline 11545 & GE54924I & NPIP & Nuclear pore complex interacting protein. \\
\hline 11877 & GE55094 & NUDCDI & HR85 islet cDNA similar 2 \\
\hline 12206 & GE55267 & ADAM28 & $\begin{array}{l}\text { Metalloendopeptidase. } \mathrm{Zn} \text { ion binding. Proteolysis. Spermatogenesis. Membrane integral. } \\
\text { Disintegrin and metalloproteinase domain } 28 \text { variant I. }\end{array}$ \\
\hline 12366 & GE553476 & IAPP & $\begin{array}{l}\text { Islet amyloid polypeptide. Like related beta-amyloid associated with Alzheimer's disease, } \\
\text { can induce apoptotic cell death. }\end{array}$ \\
\hline 12612 & GE554808 & LOC283488 & Proline-rich protein. \\
\hline
\end{tabular}


Table 3 (Continued)

\begin{tabular}{|c|c|c|c|}
\hline Identifier & Probe & Alias & Functions and comments \\
\hline 12915 & GE556336 & MYO9A & $\begin{array}{l}\text { Myosin, actin-based motor molecule, ATPase activity. Unconventional myosins, intracellular } \\
\text { movement. Regulates Rho activity in neurons. Regulation of neuronal morphology and function. }\end{array}$ \\
\hline 13339 & GE558357 & ADAM23 & $\begin{array}{l}\text { Metalloendopeptidase. Integrin binding. Proteolysis. Cell adhesion. Central nervous system } \\
\text { development. Plasma membrane integral. }\end{array}$ \\
\hline 14400 & GE563896 & B3GALTI & $\begin{array}{l}\text { UDP-Gal:betaGlcNAc beta I,3-galactosyltransferase, polypeptide I. Member of the beta- } \\
\text { I,3-galactosyltransferase gene family. Encodes type II membrane-bound glycoproteins } \\
\text { with diverse enzymatic functions using different donor substrates (UDP-galactose and } \\
\text { UDP-N-acetylglucosamine) and different acceptor sugars ( } \mathrm{N} \text {-acetylglucosamine, galactose, } \\
\mathrm{N} \text {-acetylgalactosamine). RPII-367CII.I Stratagene fetal retina. }\end{array}$ \\
\hline 14504 & GE5644I5 & - & - \\
\hline 14612 & GE56503 & HIP2 & Huntington interaction protein 2. Ubiquitin-protein ligase-like activating enzyme. Ubiquitin cycle. \\
\hline 14700 & GE565524 & DUSPI5 & Protein tyrosine-threonine-serine phosphatase. Hydrolase. \\
\hline 14740 & GE56573I & - & - \\
\hline 14756 & GE56583 & FBLIMI & Zn ion binding. Adhesion. Cell shape. Cytoskeleton. Filamin binding LIM protein I. \\
\hline 14820 & GE566190 & - & - \\
\hline 15762 & GE57। 37 & $\mathrm{KIFI} 4$ & $\begin{array}{l}\text { ATP binding. Microtubule motor and movement. Microtubule-associated complex. } \\
\text { Kinasin } 14 \text { family member. }\end{array}$ \\
\hline 16114 & GE57325 & NELLI & Structure. Ca ion binding. Cell adhesion. Nervous system development. \\
\hline 16469 & GE57516 & TNNII & $\begin{array}{l}\text { Actin and tropomyosin binding. Regulation of strital muscle contraction. } \\
\text { Muscle development. Troponin complex. Slow twitch skeletal troponin I. }\end{array}$ \\
\hline 16547 & GE57557 & CDK5 & ATP binding. Cyclin-dependent protein kinase 5 . Cell cycle. Cell proliferation. Cell division. \\
\hline 16823 & GE576963 & SESNI & Response to DNA damage stimulus. Cell cycle and proliferation arrest. Nucleus. \\
\hline 17180 & GE57883 & SELL & $\begin{array}{l}\text { Sugar binding. Cell adhesion and motility. Plasma membrane integral. Selectin-L. Lymphocyte } \\
\text { adhesion molecule I. }\end{array}$ \\
\hline 17447 & GE58018 & TFAM/ATP88 & $\begin{array}{l}\text { Transcription factor. Regulation from RNAP-I promoter. Nucleotide binding. Mg ion binding. } \\
\text { Phospholipid translocating ATPase. DNA-dep-DNA replication. Mitochondrion membrane } \\
\text { integral. Transcription factor A. }\end{array}$ \\
\hline 17879 & GE5825I4 & - & - \\
\hline 17884 & GE58255 & GCKR & Enzyme inhibitor. Glucokinase regulator. \\
\hline 17947 & GE58287 & MGAT2 & $\begin{array}{l}\text { Alpha-1,6-mannosyl-glycoprotein2-beta- } \mathrm{N} \text {-acetyl glucosaminyl transferase. } \mathrm{N} \text {-linked } \\
\text { glycosylation. Oligosaccharide biosynthesis. Membrane integral. Golgi stack. }\end{array}$ \\
\hline 17974 & GE583033 & - & - \\
\hline 18252 & GE58460 & BSMAP & $\begin{array}{l}\text { Transmembrane protein } 59 \text {-like brain-specific membrane-anchored protein. Modulates the } \\
\text { O-glycosylation and complex } \mathrm{N} \text {-glycosylation steps occurring during the Golgi maturation of } \\
\text { amyloid precursor protein. Inhibits amyloid precursor protein transport to the cell surface and } \\
\text { further shedding. C190rf4. }\end{array}$ \\
\hline 18384 & GE5853 I4 & CENTG2 & $\begin{array}{l}\text { ArfGAP with GTPase domain, ankyrin repeat, and PH domain I. GTPase-activating protein for } \\
\text { ARFI and, to a lesser extent, ARF5. ADP ribosylation factor. Directly and specifically regulates } \\
\text { adapter protein 3-dependent trafficking of proteins in the endosomal-lysosomal system. GAP } \\
\text { activity stimulated by phosphatidylinositol 3,4,5-trisphosphate (PIP3) and, to a lesser extent, by } \\
\text { phosphatidylinositol 4,5-bisphosphate (PIP2). Phosphatidic acid potentiates PIP2 stimulation. }\end{array}$ \\
\hline 18390 & GE58535 & - & Cl6Orf5. \\
\hline 18598 & GE58654 & APHIA & $\begin{array}{l}\text { Plasma membrane integral protein ectodomain proteolysis. NOTCH receptor processing. } \\
\text { Endoplasmic reticulum, Golgi stack. Anterior pharynx defective I homolog A. }\end{array}$ \\
\hline 18634 & GE586724 & - & - \\
\hline 18765 & GE587496 & BLK & ATP binding. Protein tyrosine kinase. Protein kinase cascade. \\
\hline 19105 & GE58946 & CASP3 & Cysteine-type peptidase, caspase, apoptosis induction. \\
\hline 19877 & GE59383I & MANIA2 & $\begin{array}{l}\text { Mannosyl-oligosaccharide-1,2-alpha-mannosidase. Ca ion binding. Hydrolase. Acts on glycosyl } \\
\text { bonds. Carbohydrate metabolism. N-glycan processing. Membrane integral Golgi stack. }\end{array}$ \\
\hline 20353 & GE5965I5 & PTPRK & Integral transmembrane receptor tyrosine phosphatase. Hydrolase. \\
\hline 20752 & GE59877 & PTPN6 & $\begin{array}{l}\text { Protein tyrosine phosphatase. Hydrolase. Apoptosis. G protein coupled receptor protein } \\
\text { signaling pathway. Intracellular. Cytoskeleton. Membrane. }\end{array}$ \\
\hline 20798 & GE599024 & PDZRN3 & Ubiquitin-protein ligase. $\mathrm{Zn}$ ion binding. Protein ubiquitination complex. \\
\hline 22253 & GE609375 & ZCSL3 & Heat shock protein binding. Metal ion binding. Unfolded protein binding. Protein folding. \\
\hline 22901 & GE6/3705 & - & - \\
\hline $2297 \mid$ & GE6 1413 & POLDIP2 & Nucleus. Polymerase DNA directed delta-interacting protein 2. \\
\hline 23200 & GE6I539 & SMCR7L & RP5-I I04EI5.5. \\
\hline
\end{tabular}

(Continued) 
Table 3 (Continued)

\begin{tabular}{|c|c|c|c|}
\hline Identifier & Probe & Alias & Functions and comments \\
\hline 23526 & GE6I7302 & RSAFDI & $\begin{array}{l}\text { tRNA-yW synthesizing protein I homolog. Wybutosine is a hypermodified guanosine with } \\
\text { a tricyclic base at the 3-prime position adjacent to the anticodon of phenylalanine tRNA } \\
\text { that stabilizes codon-anticodon interactions during decoding on the ribosome. Wybutosine } \\
\text { biosynthesis pathway. }\end{array}$ \\
\hline 24052 & GE620526 & FMO5 & $\begin{array}{l}\text { Mono-oxygenase. Demethyl-aniline mono-oxygenase ( } \mathrm{N} \text {-oxide forming). Electron transport. } \\
\text { Endoplasmic reticulum, microsomal. Membrane integral. }\end{array}$ \\
\hline 24282 & GE62190 & GNG3/GNG7 & $\begin{array}{l}\text { Signal transduction. Regulation of G protein coupled receptor protein signaling pathway. } \\
\text { Heterotrimeric G protein complex. Guanine nucleotide binding protein gamma-7. }\end{array}$ \\
\hline 24756 & GE62469l & - & - \\
\hline 24982 & GE626074 & ZA52P & Gastric protein uncharacterized. \\
\hline 25091 & GE62673 & AASS & $\begin{array}{l}\text { Lysine ketoglutarate reductase. Oxidoreductase. Saccharopine dehydrogenase. Electron } \\
\text { transport. Lysine catabolism. Protein tetramerization. Mitochondrial. Aminoadipate } \\
\text { semialdehyde synthase. }\end{array}$ \\
\hline 25103 & GE6268I & ROMI & Cell adhesion. Sensory and visual perception. Plasma membrane integral. \\
\hline 25830 & GE631063 & - & - \\
\hline 26034 & GE63224 & ETFA & Electron carrier and transport. Mitochondrial matrix. \\
\hline 26491 & GE636205 & HDHDIA & Haloacid dehalogenase-like hydrolase domain containing I. \\
\hline 26776 & GE644246 & SIPAILI & $\begin{array}{l}\text { Signal-induced proliferation-associated I-like protein I. Interacts with DLG4, PDLIM5, PDLIM7, } \\
\text { PROSAPIPI, actin cytoskeleton, HPV E6. Cytoplasm, cytoskeleton. Cell junction, postsynaptic } \\
\text { density at cell membrane, dendritic spines hippocampal neurons, synaptosome. }\end{array}$ \\
\hline 26936 & GE648477 & SOX5 & $\begin{array}{l}\text { SRY-related HMG box (SOX) transcription regulation factor family. DNA dependent from } \\
\text { RNAP2 promoter. Nuclear. }\end{array}$ \\
\hline 27283 & GE65539I & CDC73 & $\begin{array}{l}\text { Cell division cycle } 73 \text {, Pafl/RNA polymerase II complex component. Tumor suppressor in } \\
\text { transcriptional and post-transcriptional control pathways. Component of PAF protein complex, } \\
\text { which associates with the RNA polymerase II subunit POLR2A and a histone methyltransferase } \\
\text { complex. Facilitates association of 3' mRNA processing factors with actively transcribed } \\
\text { chromatin. Cell cycle progression through the regulation of cyclin DI/PRADI expression. }\end{array}$ \\
\hline 27415 & GE657626 & PTDSSI & Transferase. Phosphatidyl serine biosynthesis. Phospholipid biosynthesis. Membrane integral. \\
\hline 27568 & GE660354 & CI4ORFII9 & CI4ORFII9 \\
\hline 28284 & GE674I73 & GPRI6I & $\begin{array}{l}\text { Rhodopsin-like receptor. Signal transduction. G protein coupled receptor protein signaling } \\
\text { pathway. Membrane integral. }\end{array}$ \\
\hline 28369 & GE675994 & MRPL5I & $\begin{array}{l}\text { Mitochondrial ribosomal protein L5I. Encoded by nuclear genes. Mitochondrial ribosomes } \\
\text { (mitoribosomes) consist of a small } 28 \mathrm{~S} \text { subunit and a large } 39 \mathrm{~S} \text { subunit. They have an estimated } \\
75 \% \text { protein to rRNA composition compared with prokaryotic ribosomes, where this ratio is } \\
\text { reversed. No } 5 \text { S rRNA. }\end{array}$ \\
\hline 28502 & GE678706 & TTLL5 & $\begin{array}{l}\text { Tubulin tyrosine ligase-like protein family. Interacts with two glucocorticoid receptor } \\
\text { coactivators, transcriptional intermediary factor } 2 \text {, and steroid receptor coactivator I. } \\
\text { Coregulator of glucocorticoid receptor-mediated gene induction and repression. Alpha tubulin } \\
\text { polyglutamylase. Involved in the side chain initiation step of the polyglutamylation reaction not } \\
\text { elongation step. }\end{array}$ \\
\hline 28508 & GE678803 & SPG7 & $\begin{array}{l}\text { Paraplegin. Spastic paraplegia } 7 \text { (pure and complicated autosomal recessive). Cell matrix } \\
\text { adhesion regulator. This gene encodes a nuclear-encoded mitochondrial metalloprotease } \\
\text { protein that is a member of the ATPases associated with a variety of cellular activities protein } \\
\text { family. Members of this protein family share an ATPase domain and have roles in diverse } \\
\text { cellular processes including membrane trafficking, intracellular motility, organelle biogenesis, } \\
\text { protein folding, and proteolysis. Mitochondrion membrane, multipass membrane protein. }\end{array}$ \\
\hline 28991 & GE687963 & USP8 & $\begin{array}{l}\text { Cysteine-type endopeptidase. Ubiquitin thiol esterase. Ubiquitin-dependent protein catabolism. } \\
\text { Ubiquitin cycle. Cell proliferation. }\end{array}$ \\
\hline 29168 & GE69I505 & - & - \\
\hline 29917 & GE705764 & NALPI & $\begin{array}{l}\text { Nod-like receptor family, pyrin domain containing I. Death effector filament-forming CED- } \\
\text { 4-like apoptosis protein. ATP binding. Caspase recruitment domain protein } 7 \text {. Caspase } \\
\text { activator. Enzyme binding. Apoptosis induction and regulation. Defense response to pathogen. } \\
\text { Intracellular. }\end{array}$ \\
\hline 30069 & GE7086I7 & - & - \\
\hline 30107 & GE70937I & HRB & DNA, RNA, metal ion binding. mRNA export, nuclear pore. Regulation of GTPase. \\
\hline 30167 & GE7I0687 & CCDC7 & Coiled-coil domain-containing 7. \\
\hline
\end{tabular}


Table 3 (Continued)

\begin{tabular}{|c|c|c|c|}
\hline Identifier & Probe & Alias & Functions and comments \\
\hline 31250 & GE7269I6 & TBCID22A & GTPase activator. \\
\hline 31353 & GE728396 & - & - \\
\hline 31404 & GE729136 & GGAI & $\begin{array}{l}\text { Protein transporter and complex assembly. Intracellular Golgi stack protein transport. } \\
\text { Membrane. Clathrin coat of transGolgi network vesicle. }\end{array}$ \\
\hline 31632 & GE732434 & TARSL2 & Threonyl-tRNA synthetase-like protein 2 , ligase. \\
\hline 32204 & GE74064I & - & - \\
\hline 32318 & GE742294 & DMTFI & $\begin{array}{l}\text { Cyclin D binding MYB-like transcription factor I. Contains a cyclin D-binding domain, three } \\
\text { central MYB-like repeats, and two flanking acidic transactivation domains at the N-terminus } \\
\text { and C-terminus. Induced by oncogenic Ras signaling pathway and functions as a tumor } \\
\text { suppressor by activating the transcription of ARF-p53 pathway to arrest cell growth or induce } \\
\text { apoptosis. Activates transcription of aminopeptidase } \mathrm{N} \text { and plays role in hematopoietic cell } \\
\text { differentiation. Transcription regulated by binding D-cyclins. Transcriptional activator activates } \\
\text { CDKN2A/ARF locus in response to Ras-Raf signaling, thereby promoting TP53/p53-dependent } \\
\text { growth arrest. Binds to the consensus sequence } 5^{\prime} \text {-CCCG[GT]ATGT-3'. Isoform I may } \\
\text { cooperate with MYB to activate transcription of the ANPEP gene. Isoform } 2 \text { may antagonize } \\
\text { transcriptional activation by isoform I. }\end{array}$ \\
\hline 32836 & GE749435 & MSI2 & Nucleotide and RNA binding. \\
\hline 33031 & GE752199 & - & - \\
\hline 33193 & GE754378 & ELP4 & - \\
\hline 33293 & GE7556I4 & GRM3 & $\begin{array}{l}\text { Metabotropic glutamate, gamma aminobutyric acid B-like receptor. Signal transduction. } \\
\mathrm{G} \text { protein coupled receptor signaling pathway. Negative regulation of adenylcyclase. Plasma } \\
\text { membrane integral. }\end{array}$ \\
\hline 33722 & GE762426 & - & - \\
\hline 33921 & GE765425 & GRIA3 & $\begin{array}{l}\text { Glutamate receptor, ionotrophic, AMPA 3. AMPA-selective glutamate receptor } 3 \text {. Excitatory. } \\
\text { AMPA is alpha-amino-3-hydroxy-5-methyl-4-isoxazole propionate. AMPA receptors mediate } \\
\text { fast excitatory synaptic transmission in the central nervous system and play a key role in } \\
\text { hippocampal synaptic long-term potentiation and depression. }\end{array}$ \\
\hline 34083 & GE767593 & CACNB2 & $\begin{array}{l}\text { Voltage-gated Ca channel complex. Ca ion binding and transport. Neuromuscular junction } \\
\text { development. Membrane fraction. }\end{array}$ \\
\hline 34195 & GE769III & GPRI33 or GPI33 & - \\
\hline 34221 & GE769398 & $\mathrm{MSI2}$ & Nucleotide and RNA binding. \\
\hline 34239 & GE769588 & PTFIA & - \\
\hline 34398 & GE772048 & WDFYI & Phosphatidyl inositol and Zn ion binding. Nuclear. Early endosome. Cytosol. \\
\hline 35620 & GE78986 & JUB & $\begin{array}{l}\text { Component of cellular adhesive complexes. Contributes to cell fate determination and } \\
\text { regulates cell proliferation and differentiation. Involved in the regulation of actin cytoskeleton } \\
\text { dynamics and cell migration. Contributes to linking of epithelial cell junctions through } \\
\text { adhesive receptors to actin cytoskeleton. Signal transduction from cell adhesion sites to the } \\
\text { nucleus. Regulates kinase activity of AURKA/Aurora-A for mitotic commitment. Component } \\
\text { of interleukin-I signaling pathway modulating interleukin- I-induced nuclear factor kappa-B } \\
\text { activation by influencing the assembly and activity of the PRKCZ/SQSTMI/TRAF6 multiprotein } \\
\text { signaling complex. Transcription complex formation on DNA. Interacts with AURKA/Aurora-A } \\
\text { during mitosis and both proteins are phosphorylated in a complex. Interacts with CTNNAI/ } \\
\text { alpha-catenin and with F-actin. Interacts with LATS2 during mitosis and regulates organization } \\
\text { of the spindle apparatus through recruitment of gamma tubulin to the centrosome. Interacts } \\
\text { with GRB2 and PIP5 KI A. Forms a complex with SQSTMI, PRKCZ, and TRAF6. Interacts } \\
\text { with SLCI A2. Located in the cytoplasm, cytoskeleton, cell membrane, cell junction, nucleus, } \\
\text { and centrosome. Shuttles between cytoplasm and the nucleus. Localizes on centrosomes } \\
\text { during G2-M phase. Preferentially colocalizes with cadherin-adhesive complexes at sites of } \\
\text { cell-cell contact. LIM region interacts with CTNNAI. The preLIM region binds directly actin } \\
\text { filaments. LIM-2 and LIM-3 domains mediate the interaction with the N-terminal region of } \\
\text { AURKA. The association between LATS2 and JUB required the second LIM domain of JUB. } \\
\text { Belongs to the Zyxin/Ajuba family. Contains three LIM zinc-binding domains. }\end{array}$ \\
\hline 35666 & GE790167 & - & - \\
\hline 35761 & GE79076 & ULBP3 & $\begin{array}{l}\text { Major histocompatibility complex class I receptor complex. Antigen presentation. Natural killer } \\
\text { activation. Membrane. ULI 6-binding protein } 3 \text {. }\end{array}$ \\
\hline 36075 & GE79260 & RAPIA & $\begin{array}{l}\text { Small GTPase-mediated signal transduction. GTP binding. Intracellular protein transport. Cell } \\
\text { cycle. Negative regulation of cell cycle progression. Membrane. Ras oncogene family (RAPIA). }\end{array}$ \\
\hline
\end{tabular}


Table 3 (Continued)

\begin{tabular}{|c|c|c|c|}
\hline Identifier & Probe & Alias & Functions and comments \\
\hline 36101 & GE79273 & USFI & $\begin{array}{l}\text { DNA-dependent specific RNA polymerase } 2 \text { promoter transcription factor and regulator. } \\
\text { Nuclear. Upstream transcription factor I. Secretogloblin, family I A member I (uteroglobin). }\end{array}$ \\
\hline 36278 & GE79382 & RPL7A & Structural constituent of ribosome. Protein biosynthesis. Ribosome biogenesis and assembly. \\
\hline 36337 & GE794I5 & PSP & Hypothetical protein MGCI 7299. \\
\hline 36363 & GE794289 & - & - \\
\hline 36885 & GE797280 & - & - \\
\hline 36949 & GE79764 & SFRSI I/PLEKHA5 & $\begin{array}{l}\text { RNA binding. Phosphatidyl inositol binding. Nuclear mRNA splicing factor via spliceosome. } \\
\text { Arginine/Serine-rich II. Plekstrin homology domain containing family A member } 5 \text { mRNA. }\end{array}$ \\
\hline 36990 & GE79788 & SAMDI3 & - \\
\hline 37273 & GE79949I & FLJ 14167 & $\begin{array}{l}\text { KCNJNI. Potassium inwardly rectifying channel, subfamily J, member I2. Inward rectifier } \\
\text { potassium channel Kir2.2v. IRK-2. ATP-sensitive inward rectifier potassium channel I. } \\
\text { Potassium inwardly-rectifying channel, subfamily J, inhibitor I. Kir2.2v. Establishing action } \\
\text { potential waveform and excitability of neurons. Voltage dependence regulated by } \\
\text { concentration of extracellular potassium. Inwardly rectifying potassium channel blocked by } \\
\text { divalent cations. Inward rectifier potassium channels allow potassium to flow into the cell } \\
\text { rather than out of it. As external potassium is raised, the voltage range of the channel opening } \\
\text { shifts to more positive voltages. Inward rectification is due to blockage of outward current by } \\
\text { internal magnesium. Can be blocked by extracellular barium and cesium. The inward rectifier } \\
\text { potassium channel family (also known as } 2-T M \text { channels) include the strong inward rectifier } \\
\text { channels (KIR2.x), the G protein-activated inward rectifier channels (KIR3.x) and the ATP- } \\
\text { sensitive channels (KIR6.x, which combine with sulfonylurea receptors). Structurally, the pore- } \\
\text { forming subunit of KIR channels is the alpha subunit. It contains a single pore domain between } \\
\text { two membrane-spanning regions. Four alpha subunits combine to form a tetramer, with the } \\
\text { pore domain of each subunit contributing to the structure of the central pore. Heteromeric } \\
\text { channels can also be formed within subfamilies, eg, KIR3.2 with KIR3.3. }\end{array}$ \\
\hline 38007 & GE80398 & AKRICI/AKRIC2 & $\begin{array}{l}\text { Aldo-keto reductase family I, member C2. Electron transporter. Bile acid transporter. } \\
\text { Oxidoreductase. 20-alpha-hydroxy-steroid dehydrogenase. Trans-I,2-dehdrobenzene- } \\
\text { I,2-diol dehydrogenase. Xenobiotic and lipid metabolism. Transport. Digestion. Steroid } \\
\text { metabolism. Dehydrodiol dehydrogenase 2. Bile acid binding protein. 3-alpha-hydroxysteroid } \\
\text { dehydrogenase type } 3 \text { (AKRIC2) transcript variant I mRNA. Canalicular bile acid transport. } \\
\text { Cytoplasm. AKRICI mRNA. }\end{array}$ \\
\hline 38049 & GE80426I & LOC285626 & Hypothetical protein. \\
\hline 38070 & GE804386 & RP9 & $\begin{array}{l}\text { Metal ion binding. Sensory and visual perception. RNA splicing. Nuclear. Retinitis pigmentosa. } \\
\text { Autosomal dominant. }\end{array}$ \\
\hline 38729 & GE8084I 7 & TXNL6 & Thioredoxin-like protein 6. Nucleoredoxin-like protein. Rod-derived cone viability factor. \\
\hline 38739 & GE80847 & TGM7 & $\begin{array}{l}\text { Gamma glutamyl transferase. Ca ion binding. Acyl transferase. Peptide cross-linking. } \\
\text { Transglutaminase } 7 .\end{array}$ \\
\hline 38813 & GE80890 & COL5AI & $\begin{array}{l}\text { Extracellular matrix structural constituent. Heparin binding. Phosphate transport. Cell } \\
\text { adhesion. Collagen type } \mathrm{V} \text { alpha I. Cytoplasm. }\end{array}$ \\
\hline 38882 & GE80930I & - & - \\
\hline 39376 & GE8I 2224 & MGC39606 & Hypothetical protein. Nonprotein coding RNA 86. Cytogenetic band Xq26.3. \\
\hline 39516 & GE8I3I 26 & - & - \\
\hline 39690 & GE81418 & SULT2BI & $\begin{array}{l}\text { Alcohol steroid sulfotransferase. Lipid and steroid metabolism. Cytoplasm. Sulfotransferase } \\
\text { family, cytosolic, } 2 \text { B, member I. }\end{array}$ \\
\hline 39743 & GE8I449 & GDFI5 & $\begin{array}{l}\text { Cytokine. Growth factor. Signal transduction. Transforming growth factor beta-receptor } \\
\text { signaling pathway. Cell-cell signaling. Extracellular space. Growth differentiation } \\
\text { factor } 15 .\end{array}$ \\
\hline 40333 & GE81822 & PYCR2 & $\begin{array}{l}\text { Pyrroline-5-carboxylate reductase family member } 2 \text {. Oxidoreductase. Electron transport. } \\
\text { Proline biosysthesis. }\end{array}$ \\
\hline 40551 & GE819522 & - & - \\
\hline 40642 & GE820II4 & KIAAI 370 & Hypothetical protein. LOC5620. \\
\hline 40690 & GE820397 & - & - \\
\hline 41169 & GE82307 & IQCC & IQ motif-containing $\mathrm{C}$. \\
\hline 41665 & GE82602 & HOXDII/HOXDIO & $\begin{array}{l}\text { Transcription factor related to RNAP II. Development. Nuclear. Homeobox DI I/I0. } \\
\text { Development. }\end{array}$ \\
\hline 41868 & GE82723 & DGCR8 & Double-stranded RNA binding. DiGeorge syndrome, critical region gene 8. \\
\hline 41968 & GE82785 & C7ORF26 & Chromosome 7 Orf 26. \\
\hline
\end{tabular}

(Continued) 
Table 3 (Continued)

\begin{tabular}{|c|c|c|c|}
\hline Identifier & Probe & Alias & Functions and comments \\
\hline 42072 & GE82842 & NOX5 & NADPH oxidase, EF hand Ca binding domain 5. \\
\hline 42550 & GE83II60 & - & - \\
\hline 42718 & GE832I43 & MSI2 & RNA binding. \\
\hline 42726 & GE832। 8 & APBA2BP & $\begin{array}{l}\text { Amyloid beta (A4) precursor protein binding family A member } 2 \text { binding protein. Transcript } \\
\text { variants I and } 2 \text {. Ca ion binding. Oxidoreductase. Protein secretion. Antibiotic biosynthesis. } \\
\text { Protein metabolism. Regulation of amyloid precursor protein biosynthesis. Golgi cysternae. } \\
\text { Nuclear. Cytoplasm. Endoplasmic reticulum membrane. }\end{array}$ \\
\hline 42766 & GE83242I & ACOT6 & Acyl-CoA thioesterase 6. \\
\hline 42791 & GE83256 & NRIP2 & Nuclear receptor interacting protein 2. \\
\hline 43138 & GE83463 & ATP2B4 & Hypothetical protein. MGC5457, mRNA. \\
\hline 43379 & GE836II & NYD-SP26 & Testis development protein. \\
\hline 43489 & GE83679 & SLAMF6 & SLAM family member 6. CD2 surface receptor. Membrane integral. \\
\hline 43664 & GE837848 & KCMKI2 & Voltage-gated $\mathrm{K}$ ion channel transport. Membrane integral. \\
\hline 44056 & GE840II & - & - \\
\hline 44077 & GE84023 & TGM2 & $\begin{array}{l}\text { Protein-glutamine. Gamma glutamyl transferase. Ca ion binding. GTP binding. Acyl transferase. } \\
\text { G protein coupled receptor. Signaling pathway. Peptide cross-linking. Positive regulation of cell } \\
\text { adhesion. Extracellular matrix. Cytosol. Membrane. }\end{array}$ \\
\hline 44304 & GE84I56 & - & - \\
\hline 44579 & GE843I74 & - & - \\
\hline 44682 & GE8438I & - & - \\
\hline 44855 & GE84488 & - & - \\
\hline 45018 & GE84584 & - & - \\
\hline 45247 & GE847267 & SLC44A5 & Solute carrier family 44 , member 5 ; choline transporter-like protein 5. \\
\hline 45905 & GE85II7 & NARF & $\begin{array}{l}\text { Nuclear prelamin A recognition factor. Similarity to iron-only hydrogenase-like protein } 2 . \\
\text { Prenyl-dependent prelamin A binding protein. Prenylation and farnesylation at carboxyl } \\
\text { terminal end for membrane attachment and protein interactions. On cysteine residue of } \\
\text { carboxyl-terminal CaaX motif. Component of a prelamin A endoprotease complex. Cysteine } \\
\text { residue is removed from prelamin A when it is endoproteolytically processed into mature } \\
\text { lamin A. Co-localizes with the nuclear lamina. }\end{array}$ \\
\hline 46183 & GE852630 & - & - \\
\hline 46298 & GE8533। I & KIAA0922 & Transmembrane protein $|\mathrm{I}|$-like isoform- $\mathrm{I}$. \\
\hline 47318 & GE859187 & - & - \\
\hline 47492 & GE86023 & EIF4A2 & $\begin{array}{l}\text { DNA and RNA binding. Translation initiation factor. Protein biosynthesis. Regulation of } \\
\text { translational initiation. Eukaryotic translation initiation factor } 4 \mathrm{~F} \text { complex. }\end{array}$ \\
\hline 47510 & GE86033 & DNAJC3 & $\begin{array}{l}\text { DnaJ (Hsp40) homolog, subfamily C, member } 3 \text {. Interferon-induced, double-stranded } \\
\text { RNA-activated protein kinase) inhibitor. Tetratricopeptide repeat family of proteins. Highly } \\
\text { conserved J domain found in DNAJ chaperone family members. Involved in the unfolded } \\
\text { protein response during endoplasmic reticulum stress. Co-chaperone of HSPA8/HSC70, } \\
\text { stimulates its ATPase activity. Inhibits both autophosphorylation of EIF2 AK2/PKR and the } \\
\text { ability of EIF2 AK2 to catalyze phosphorylation of the EIF2 A. Inhibits EIF2 AK3/PERK activity. }\end{array}$ \\
\hline 47839 & GE86226 & RPS23 & Structural constituent of ribosome. Protein biosynthesis. Small ribosomal subunit protein S23. \\
\hline 47990 & GE863I 23 & - & - \\
\hline 48005 & GE86324 & TMEDI & Transmembrane emp-24 domain-containing I. \\
\hline 48087 & GE86373I & SLC36A4 & Solute carrier family 36 (proton/amino acid symporter), member 4. \\
\hline 48127 & GE86393 & ATP2A2 & $\begin{array}{l}\text { ATP, Mg, and Ca ion binding. Calcium transport ATPase. Hydrolase acts on acid anhydrides. } \\
\text { Transmembrane transporter. Cation transport. Cell adhesion. Metabolism. Epidermis } \\
\text { development. Membrane fraction. Microsome. Plasma membrane integral. Sarcoplasmic } \\
\text { reticulum. }\end{array}$ \\
\hline 48128 & GE86394 & CSNKIE & $\begin{array}{l}\text { Nucleotide binding. Protein serine/threonine kinase. Casein kinase I. Protein Tyrosine kinase. } \\
\text { DNA repair. Signal transduction. Casein kinase I epsilon. }\end{array}$ \\
\hline 48161 & GE86416 & FDFTI & $\begin{array}{l}\text { Mg ion binding. Farnesyl diphosphate farnesyl transferase. Oxidoreductase. Cholesterol } \\
\text { biosynthesis. Isoprenoid biosynthesis. Membrane integral. }\end{array}$ \\
\hline 48356 & GE865354 & MGC39606 & Nonprotein coding RNA 86. Xq26.3 chromosome band location. NCRNA00086. \\
\hline 48491 & GE866I4 & OR2T35/OR2T2 & $\begin{array}{l}\text { Olfactory receptor. Signal transduction. G protein coupled receptor. Sensory olfactory } \\
\text { perception. Membrane integral. Olfactory receptor, family } 2 \text {, subfamily T, members } 35 \text { and } 2 \text {. }\end{array}$ \\
\hline 49316 & GE87 1079 & KIAAI026 & Kazrin isoform A. \\
\hline 49481 & GE872II & - & - \\
\hline
\end{tabular}


Table 3 (Continued)

\begin{tabular}{|c|c|c|c|}
\hline Identifier & Probe & Alias & Functions and comments \\
\hline 49512 & GE87230 & LRFN5 & Leucine-rich repeat and fibronectin type 3 domain-containing 5 . \\
\hline 49941 & GE87458 & FKSG24 & Hypothetical protein. MGCI2972 (FKSG24). \\
\hline 51072 & GE880744 & KIAAI 754 & Inositol I,4,5-triphosphate receptor interacting protein. ITPRIP. Danger. \\
\hline 51170 & GE88I33 & SL336 A4 & Solute carrier family 36 (proton/amino acid symporter), member 4. \\
\hline 51284 & GE88203 & SLC9 A9 & $\begin{array}{l}\text { Sodium:hydrogen antiporter. Solute: hydrogen. Sodium ion binding. Sodium ion transport. } \\
\text { Regulation of } \mathrm{pH} \text {. Membrane integral. Solute carrier family } 9 \text { (sodium/hydrogen exchanger) } \\
\text { isoform } 9 .\end{array}$ \\
\hline 51549 & GE88364 & MAPKII & $\begin{array}{l}\text { ATP binding. Protein serine/threonine kinase. MAP kinase. MP kinase and transferase. } \\
\text { Response to stress. Signal transduction. Protein kinase cascade. Antimicrobial humoral } \\
\text { response. Mitogen-activated protein kinase II. }\end{array}$ \\
\hline 52061 & GE88659 & ZNRF2 & Zinc and ring finger 2. \\
\hline 52255 & GE887730 & - & - \\
\hline 52268 & GE88782 & CIOORFII8 & CTCL tumor antigen HD-CL-0I/LI4-2. \\
\hline 52992 & GE894844 & GYPA & $\begin{array}{l}\text { Glycophorin A sialoglycoprotein of the human erythrocyte membrane. Receptor for influenza } \\
\text { virus and hepatitis A virus. Affects function of SLC4AI. }\end{array}$ \\
\hline 53339 & GE898I57 & HNRPAIP5 & Heterogeneous nuclear ribonucleoprotein AI pseudogene 5. \\
\hline 53778 & GE902064 & - & - \\
\hline 54138 & GE905236 & ABCBII & $\begin{array}{l}\text { ATP-binding cassette, subfamily B (MDR/TAP), member II. Membrane-associated protein. } \\
\text { Member of the superfamily of ATP-binding cassette transporters that transport various } \\
\text { molecules across extracellular and intracellular membranes. MDR/TAP subfamily involved in } \\
\text { multidrug resistance. }\end{array}$ \\
\hline
\end{tabular}

pathway, signal transduction, signaling transforming growth factor- $\beta$, signaling immediate early, spliceosome, splicing factor, splicing factor RNA, synaptic function, trafficking endolysosomal system, trafficking protein, transcription factor, transcription factor upstream, transcription factor antagonist, transcription promoter, transcription regulation at RNAP-1 promoter, transcription regulation at RNAP-2, transcription, homeobox (development), binding nucleotide, transferase acyl, transferase farnesyl, transferase steroid sulfo, transport antiporter (sodium-hydrogen), transport cation, transport carrier solute, transport intracellular, transport lipid, transport membrane associated, transport metal ion, transport multidrug resistance, transport neurotransmitter, transport phosphate, transport phospholipid, transport mRNA, transport protein, transport symporter amino acid, tRNA ligase, tRNA nucleotide modification, tRNA synthase, tubulin, tumor antigen, ubiquitin protein catabolism, ubiquitin cycle, ubiquitin pathway, and zinc finger.

\section{Pathways}

Figure 1 illustrates typical pathways and connections among seven select genes. The seven genes are $A P O B, N E C A B 3$ (APBA2BP), GRIA3, IAPP, HOXD10, UBE2K, and NELL1. Gene functions are shown in Table 3. The seven genes and their interconnected related pathways are: $A P O B, I A P P$, and NECAB3 (Apba2BP), the beta-amyloid pathway; HOXD10 and $U B E 2 K$, the ubiquitination pathway; GRIA3, other glutamate receptors; and $N E L L 1$, signaling and amyloid production. These seven genes are interconnected via genes (inserted by the GenePro program) in overlapping pathways that broadly include signaling, transcription, amyloid, and ubiquitination pathways. Similarly, interconnections and pathways may be produced for the other 143 genes in Table 3, that are too numerous and complex to show in one figure.

\section{Discussion}

Of the 197 genes that showed significant expression changes in HAD/HIVE, HAD alone, HIVE alone, versus $\mathrm{HIV}^{+}, 150$ genes were identified. These genes were members of 159 groups and functions. It is beyond the scope of this article to analyze the genes in detail and the ramifications of the disease state within which gene expression varied significantly. The groups and functions, within which the genes fall, overlap many of the cellular processes in neurons. Although several of these cellular processes may not be considered neuron-specific, they are most likely expressed as part of the stress and attempt-atrecovery processes that the neurons exhibit in HAD/HIVE, HAD, and HIVE, compared with the control $\mathrm{HIV}^{+}$.

Broadly, the categories (with some descriptors) include adhesion (intercellular interactions), amyloid (implicated in damage to cognition in Alzheimer's disease), apoptosis (neuronal dysfunction and cell death, also certainly associated with the end state of loss of cognition), binding (of various metal and biochemical ions, crucial in cellular processes), channel complexes (components of ion transport within cells and the plasma membrane), cell cycle (attempts 


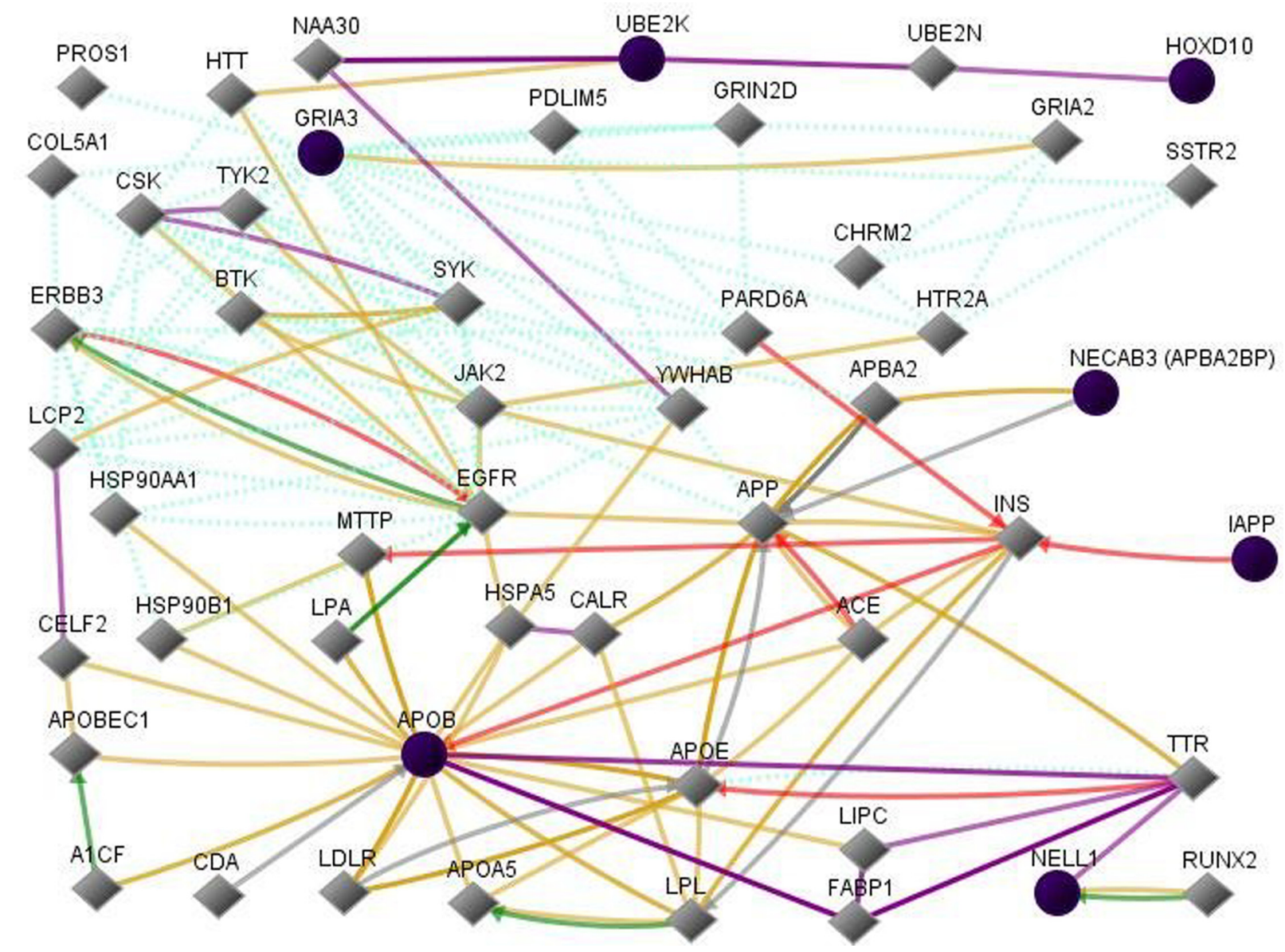

Figure I Pathway connections among APOB, NECAB3 (APBA2BP), GRIA3, IAPP, HOXDIO, UBE2K, and NELLI. The seven genes are indicated by solid circles. Diamonds indicate neighboring genes inserted by the GenePro program. Arrowheads indicate directional effects. The colors indicate the following: red, downregulation of function and transcription; green, upregulation of function and transcription; gray, regulation exists but direction unknown as yet; beige, gene products directly interact; dotted light blue, predicted protein-protein interaction; and purple, correlated expression detected by microarray experiments. ${ }^{46}$ The seven genes are selected as representative of pathways including signaling, transcription, amyloid, and ubiquitination.

by the cell to expel noxious molecules through shutdown or traversing the cell division cycle), chaperone (assisting proteins to attain and maintain functional conformations), chromatin (central in transcription, genome maintenance and repair, and epigenetics), cytokines (inflammation), cytoskeleton, filaments, and matrix (scaffolding and intracellular transport), diGeorge syndrome (genes involved in brain development), and Huntington's disease (trinucleotide repeats that result in gene dysfunction), metabolism (breakdown of biochemical and cell components), mitochondria (energy production for the cell and also proteins needed for mitochondrion function and survival), multinetwork detection protein or RNA (proteins or RNAs that are involved in multiple different molecular pathways and networks), sensory perception (in this study, visual-related and olfactoryrelated protein expression was perturbed), receptor (binding that is required prior to an effect being exerted, signaling, by proteins and solutes), ribosome and tRNA (key elements in protein synthesis), noncoding miRNA (a novel realm in the control of gene expression), signaling (intracellular and extracellular molecular pathways), splicing (transcription), synapse (crucial in neuron function), transcription factor (proteins involved in initiation and process of transcription), transport (intracellular and intercellular movement of proteins and ionic and nonionic solutes), multidrug resistance (a process by which cells become resistant to drugs by shutting down their transport), and ubiquitin cycle (protein turnover). In addition, it should be noted that the ubiquitin pathway marks proteins for metabolism and degradation, whereas chaperones assist proteins to attain their optimal functional states. ${ }^{26,49}$ We hypothesize the existence of multinetwork detection proteins and RNAs. Such proteins and RNAs would be involved in multiple unrelated molecular pathways and networks. This is consequently different from proteins that are involved in multiple, but related, pathways or homeobox transcription genes of development. For 
example, MYO9A may be a multinetwork detection protein because it interacts with myosin filaments and actin-based motor molecules involved in intracellular movement, has ATPase activity, and regulates rho activity, integrin binding, proteolysis, cell adhesion, and central nervous system development. ${ }^{45,46}$

Potentially devastating effects for neuronal function and survival could result from gene expression changes in beta-amyloid-like protein and amyloid beta-A4 precursor protein binding family A member 2 binding protein. The effects of the former may be due to its amyloid-like properties and the effects of the latter, changes that may occur in amyloid precursor protein metabolism and signaling, due to changes in the receptor protein expression. In addition, changes in apolipoprotein B expression could be associated with dementia in NeuroAIDS as it is in Alzheimer's disease. ${ }^{50}$ Severe changes in gene expression are anticipated, due to the stress that results from chronic HIV-1 infection of the brain. Accordingly, expression of glycophorin A is an example of such severe changes that can possibly occur in the neuron in NeuroAIDS. Glycophorin is a well known component of red blood cell membranes. The RNA that is purified in our procedures is free of all proteins and the detection method used is purely nucleic acid. Moreover, even if glycophorin mRNA were present in mature circulating red blood cells, red blood cells would not be present in our neuronal preparations, because we excise neurons from 10 micron thick sections (ie, smaller than the diameter of these neurons), the neurons are clearly identified with Nissl stain, and are the only cells with nucleoli in these sections. In addition, there were no endothelial cells associated with the neurons because of precision of excision by the laser beam. Likewise, red blood cells would be even further away from the excised neurons and well outside the laser excision perimeter. This greatly reduces the possibility of purifying and amplifying mRNA for glycophorin from red blood cells or any other potentially contaminating cells in our preparations. The glycophorin or glycophorin-like RNA that we detected, in all likelihood, is derived from anomalous glycophorin gene expression in the neurons we analyzed. Also, this is most likely due to the stress undergone by these neurons in their chronic state of disease.

This study is an initial step towards identifying specific genes in neuroanatomically specific neurons that may be involved in neurodegenerative processes that result from HIV-1 infection of the brain. Moreover, a wide range of biochemical processes in the health and maintenance of the cell are dysregulated. Some genes are novel, including for multinetwork detection proteins. This line of investigation is useful and will provide further specific information about dysfunction of gene expression in HAND.

\section{Conclusion}

Novel directions in the analysis and categorization of the transcriptome in disease and health are under development for HAND. For example, systems biological approaches are being developed to elucidate transcriptome organization patterns that are highly correlated across samples and that identify groups of genes or modules. ${ }^{51}$ In addition, future prospective studies should be designed to answer additional questions, for example, related to virus load, symptomatology, as well as comparisons across the different stages in the evolution of diagnostic criteria for NeuroAIDS. It will also be of use to validate the data with additional patient cohorts.

\section{Acknowledgments}

The Diabetes Research Institute (University of Miami Miller School of Medicine, Miami, FL) is thanked for the use of their Leica laser microdissection microscope for the current study. Drs Michael Falduto, John Trumbull, and Scott Magnusson (GenUS Biosystems, Chicago, IL) are thanked for their helpful discussions and performing the microarray analysis. We also thank Dr Alexander Wang (NCBI, Bethesda, MD) and Dr George J Quellhorst (SABiosciences Corp, Frederick, MD) for helpful discussions. We thank the National NeuroAIDS Bank (UCLA School of Medicine, Los Angeles, CA), Dr Susan Morgello (Manhattan HIV Brain Bank, Mt Sinai Medical Center, New York, NY), Dr Igor Grant (NeuroAIDS Brain Bank, UCSD School of Medicine, San Diego, CA) and the National NeuroAIDS Tissue Consortium (National Institutes of Health, Bethesda, MD) for the cryopreserved brain tissue utilized in this study. We thank Dr J McArthur and Dr C Pardo (Johns Hopkins School of Medicine, Baltimore, MD) for help with cryosectioning the brain tissue used in this study. Support for this work included National Institutes of Health grants to PS, ES, DC, and AJL. PS also thanks the Division of Infectious Diseases and International Medicine for its support.

\section{Disclosure}

The authors report no conflicts of interest in this work.

\section{References}

1. Petito CK, Kerza-Kwiatecki AP, Gendelman HE, et al. Neuronal injury in HIV infection. J Neurovirol. 1999;5:327-341.

2. Kaul M. HIV-1 associated dementia: Update on pathological mechanisms and therapeutic approaches. Curr Opin Neurol. 2009;22:315-320. 
3. Minagar A, Shapshak P. HIV-associated Dementia: Clinical Features and Pathogenesis in NeuroAIDS. Hauppauge, NY: Nova Science Publishing; 2006.

4. Minagar A, Commins D, Alexander JS, et al. NeuroAIDS: Characteristics and diagnosis of the neurological complications of AIDS. Mol Diagn Ther. 2008;12:25-43.

5. Shapshak P, Kangueane P, Fujimura RK, et al. Editorial NeuroAIDS Review. AIDS. 2011;25:123-141.

6. Antinori A, Arendt G, Becker JT, et al. Updated research nosology for HIV associated neurocognitive disorders. Neurology. 2007;69 1789-1799.

7. Cysique LA, Maruff P, Brew BJ. Prevalence and pattern of neuropsychological impairment in human immunodeficiency virusinfected/acquired immunodeficiency syndrome (HIV/AIDS) patients across pre- and post-highly active antiretroviral therapy eras: A combined study of two cohorts. J Neurovirol. 2004;10:350-357.

8. McArthur JC. HIV dementia: An evolving disease. J Neuroimmunol. 2004:157:3-10.

9. Tozzi V, Balestra P, Lorenzini P, et al. Prevalence and risk factors for human immunodeficiency virus-associated neurocognitive impairment, 1996 to 2002: Results from an urban observational cohort. J Neurovirol. 2005;11:265-273.

10. Kopniski KL, Jing Bao, Lin YW. Neurobiology of HIV, psychiatric and substance abuse comorbidity research: Workshop report. Brain Behav Immun. 2007;21:428-441.

11. Budka H. The neuropathology of HIV-associated brain disease. In: Gendelman HE, Grant I, Everall I, Lipton SA, Switzer S, editors The Neurology of AIDS. New York, NY: Oxford University Press; 2005.

12. Arendt G, von Giesen HJ. Human immunodeficiency virus dementia: Evidence of a subcortical process from studies of fine finger movements. J Neurovirol. 2002;8 Suppl 2:27-32.

13. Cherner M, Masliah E, Ellis RJ, et al. Neurocognitive dysfunction predicts postmortem findings of HIV encephalitis. Neurology. 2002;59: 1563-1567.

14. Persidsky Y, Gendelman HE. Mononuclear phagocyte immunity and the neuropathogenesis of HIV-1 infection. J Leukoc Biol. 2003; 74:691-701.

15. Sperber K, Shao L. Neurologic consequences of HIV infection in the era of HAART. AIDS Patient Care STDS. 2003;17:509-518.

16. Mattson MP, Haughey NJ, Nath A. Cell death in HIV dementia. Cell Death Differ. 2005;12 Suppl 1:893-904.

17. Persidsky Y, Poluektova L. Immune privilege and HIV-1 persistence in the CNS. Immunol Rev. 2006;213:180-194.

18. Minagar A, Shapshak P, Duran EM, et al. Gene expression in HIVassociated dementia, Alzheimer's disease, multiple sclerosis, and schizophrenia. J Neurol Sci. 2004;224:3-17.

19. Shapshak P, Minagar A, Duran EM, et al. Gene expression in HIV associated dementia. In: Minagar A, Alexander JS, editors. Inflammatory Disorders of the Nervous System, Clinical Aspects, Pathogenesis, and Management. Totowa, NJ: Humana Press; 2005.

20. Shapshak P, Duncan R, Torres-Munoz JE, Duran EM, Minagar A, Petito CK. Analytic approaches to differential gene expression in AIDS vs control brains. Front Biosci. 2004;9:2935-2946.

21. Shapshak P, Duncan R, Minagar A, et al. Elevated expression of IFN-gamma in the HIV-1 infected brain. Front Biosci. 2004;9: 1073-1081.

22. Masliah E, Roberts ES, Langford D, et al. Patterns of gene dysregulation in the frontal cortex of patients with HIV encephalitis. J Neuroimmunol. 2004;157:163-175.

23. Borjabad A, Brooks AI, Volsky DJ. Gene expression profiles of HIV-1-infected glia and brain: Toward better understanding of the role of astrocytes in HIV-1-associated neurocognitive disorders. J Neuroimmune Pharmacol. 2010;5:44-62.

24. Galey D, Becker K, Haughey N, et al. Differential transcriptional regulation by human immunodeficiency virus type 1 and gp120 in human astrocytes. J Neurovirol. 2003;9:358-371.
25. Shapshak P, Duncan R, Nath A, et al. Gene chromosomal organization and expression in cultured human neurons exposed to cocaine and HIV-1 proteins gp120 and tat: Drug abuse and NeuroAIDS. Front Biosci. 2006;11:1774-1793.

26. Gelman BB, Schuenke KW. Brain aging in AIDS: Increased ubiquitinprotein conjugate and correlation with decreased synaptic protein but not A $\beta$-stained diffuse plaque. J Neurovirol. 2004;10:98-108.

27. Gelman BB, Soukup VM, Schuenke KW, et al. Acquired neuronal channelopathies in HIV-associated dementia. J Neuroimmunol. 2004; 157:111-119.

28. Gartner S. Mechanisms of HIV entry into the CNS. In: Minagar A, Shapshak P, editors. Neuro-AIDS. New York, NY: Nova Scientific Publishing Inc; 2006.

29. Shapshak P, Stewart RV, Rodriguez de la Vega P, et al. Brain macrophage surface marker expression with HIV-1 infection and drug abuse: A preliminary study. J NeuroAIDS. 2003;2:37-50.

30. Pulliam L, Bing Suna B, Hans Rempela H. Invasive chronic inflammatory monocyte phenotype in subjects with high HIV-1 viral load. J Neuroimmunol. 2004;157:93-98.

31. Roberts ES, Zandonatti MA, Watry DD, et al. Induction of pathogenic sets of genes in macrophages and neurons in NeuroAIDS. Am J Pathol. 2003;162:2041-2057.

32. Torres-Munoz J, Stockton P, Tacronte N, Roberts B, Maronpot RR, Petito CK. Detection of HIV-1 gene sequences in hippocampal neurons isolated from postmortem AIDS brains by laser capture microdissection. J Neuropathol Exp Neurol. 2001;60:885-892.

33. Trillo-Pazos G, Diamanturos A, Rislove L, et al. Detection of HIV-1 DNA in microglia/macrophages, astrocytes and neurons isolated from brain tissue with HIV-1 encephalitis by laser capture microdissection. Brain Pathol. 2003;13:144-154.

34. Thompson KA, Churchill MJ, Gorry PR, et al. Astrocyte specific viral strains in HIV dementia. Ann Neurol. 2004;56:6873-6877.

35. Standaert DG. Applications of laser capture microdissection in the study of neurodegenerative disease. Arch Neurol. 2005;62:203-205.

36. Burgoon MP, Keays KM, Owens GP, et al. Laser-capture microdissection of plasma cells from subacute sclerosing panencephalitis brain reveals intrathecal disease-relevant antibodies. Proc Natl Acad Sci U S A. 2005;102:7245-7450.

37. Churchill MJ, Gorry PR, Cowley D, et al. Use of laser capture microdissection to detect integrated HIV-1 DNA in macrophages and astrocytes from autopsy brain tissues. $J$ Neurovirol. 2006;12:146-152.

38. Lu L, Neff F, Fischer DA, et al. Regional vulnerability of mesencephalic dopaminergic neurons prone to degenerate in Parkinson's disease: A post-mortem study in human control subjects. Neurobiol Dis. 2006; 23:409-421.

39. Duran EM, Shapshak P, Worley J, et al. Presenilin-1 detection in brain neurons and Foxp3 in peripheral blood mononuclear cells: Normalizer gene selection for real time reverse transcriptase PCR using the $\Delta \Delta \mathrm{Ct}$ method. Front Biosci. 2005;10:2955-2965.

40. Morgello S, Gelman BB, Grant E, Singer E, Vinters H, Kozlowski P. The National NeuroAIDS Tissue Consortium. Neuropathol Appl Neurobiol. 2001;27:326-335.

41. National NeuroAIDS Tissue Consortium. Available from: http://spitfire. emmes.com/study/hbb/ and http://www.nntc.org/. Accessed May 9, 2011.

42. No authors listed. Nomenclature and research case definitions for neurologic manifestations of human immunodeficiency virustype 1 (HIV-1) infection. Report of a Working Group of the American Academy of Neurology AIDS Task Force. Neurology. 1991;41: 778-785.

43. CodeLink GenUS Biosystems chip. Available from: http://www. genusbiosystems.com/. Accessed May 9, 2011.

44. CodeLink chip information. Available from: http://dl.dropbox.com/ u/2206738/Codelink\%20Human\%20022311.xls.zip. Accessed May 9, 2011.

45. National Center for Biotechnology Information. Available from: http:// www.ncbi.nlm.nih.gov/. Accessed May 9, 2011. 
46. Gene Cards. Available from: http://www.genecards.org/. Accessed May 9, 2011.

47. GenePro SA Biosciences. Available from: http://gncpro.sabiosciences. com/gncpro/gncpro.php. Accessed May 9, 2011.

48. Ariadne Pathways Assist. Available from: http://www.ariadnegenomics. com/. Accessed May 9, 2011.

49. Douglas NR, Reissmann S, Zhang J, et al. Dual action of ATP hydrolysis couples lid closure to substrate release into the group II chaperonin chamber. Cell. 2011;144:240-252.
50. Xu J, Ikezu T. The comorbidity of HIV-associated neurocognitive disorders and Alzheimer's disease: A foreseeable medical challenge in post-HAART era. J Neuroimmune Pharmacol. 2009;4:200-212.

51. Oldham MC, Konopka G, Iwamoto K, et al. Functional organization of the transcriptome in human brain. Nat Neurosci. 2008;11:1271-1282.

Neurobehavioral HIV Medicine

Dovepress

\section{Publish your work in this journal}

Neurobehavioral HIV Medicine is an international, peer-reviewed, open access journal focusing on advances in research in HIV/ AIDS, with specific reference to the neurological, psychiatric and behavioral consequences of the disease, concomitant infections and specific antiretroviral therapy. The manuscript management system is completely online and includes a very quick and fair peer-review system, which is all easy to use Visit http://www.dovepress.com/testimonials.php to read real quotes from published authors. 